\title{
A morfogênese espacial da antiga Báctria: interações e paradigmas em uma paisagem fractal
}

\author{
Cibele Elisa Viegas Aldrovandi (*)
}

\begin{abstract}
ALDROVANDI, C.E.V. A morfogênese espacial da antiga Báctria: interações e paradigmas em uma paisagem fractal. Revista do Museu de Arqueologia e Etnologia, São Paulo, 20: 163-196, 2010.
\end{abstract}

Resumo: A partir dos resultados das escavações e das prospecções arqueológicas realizadas na década de 1970 na porção oriental da antiga Báctria, apresentamos uma análise quantitativa acerca da morfogênese espacial desta região, em uma escala sincrônica e diacrônica, perfazendo aproximadamente três milênios de história da Ásia Central, a partir da Idade do Bronze até o Periodo Kushan. Esse quadro analítico, baseado em uma perspectiva da Arqueologia do Espaço, permite examinar o impacto do advento greco-bactriano nesta paisagem, assim como avaliar algumas das principais questões que permeiam o discurso paradigmático acerca da interação entre os gregos e as demais populações que habitaram a Báctria na antiguidade.

Palavras-Chave: Báctria - Ai-Khanum - Morfogênese do espaço Ambiente construido - Paisagem fractal.

\section{Introdução}

$\mathrm{D}$ evo, então, começar pela Índia (...). De qualquer maneira, Apolodoro, que escreveu as Párticas, ao mencionar os gregos que fizeram a Báctria se revoltar contra os reis sírios, que sucede. ram Seleucus Nicator, diz que, quando estes reis ampliaram seu poder, eles também atacaram a Índia (...); que Eucratidas manteve ao menos mil cidades sob seu jugo. Outros autores, entretanto, dizem que somente as tribos entre o Hidaspes e o Hipanis eram nove, em número, e que mantinham cinco mil cidades, nenhuma delas menor que a Cos

(*) Pós-doutorado pelo Museu de Arqueologia e Etnologia da Universidade de São Paulo. aldrovan@yahoo.com meropiana, e que Alexandre subjugou essa região e a entregou a Porus.

[Estrabão, Geografia XV.1.1-3] ${ }^{1}$

O império extremamente próspero da Báctria das mil cidades.

[Justino XLI.1.8] $]^{2}$

A antiga Báctria, região situada no sul da Ásia Central - em uma área estratégica que

(1) Tradução nossa, a partir de: The Geography of Strabo, XV-XVI, Jones, H. L. (trad.). The Loeb Classical Library, VII, Jeffrey Henderson (Ed.). Harvard University Press, Cambridge, Mass. (1930) 2000: 3-7.

(2) Tradução nossa, a partir de M. J. Justinus, Epitoma Historiarum Philippicarum, disponivel em <http://www.thelatinlibrary.com/justin/41.html>, acesso em: setembro de 2008 . 
pertence atualmente ao Afeganistão e a porç̃es do Turcomenistão, Uzbequistão e Tadjiquistão -, é uma das mais longinquas e menos conhecidas regiões asiáticas conquistadas pelos exércitos de Alexandre, o Grande, após as sucessivas campanhas contra os persas (Fig. 1). Esta antiga satrapia do Império Aquemênida pertenceu, em seguida, aos selêucidas e tornou-se, posteriormente, um reino independente governado por dinastias greco-bactrianas. Os historiadores ocidentais frequentemente consideraram este periodo um "capitulo perdido" da história Helenística (Tarn 1951; Holt 1984; Pollitt 1986). Não obstante a escassez de fontes textuais a seu respeito - estas mesmas pouco confiáveis, como nos adverte o próprio Estrabão no trecho supracitado -, a evidência material profusa particularmente, a numismática -, contribuiu para que essa região e as genealogias dinásticas greco-bactrianas povoassem o imaginário dos historiadores clássicos (ver Allchin 1957: 131; Boardman 2007: 9-10). Esses, por sua vez, inspiraram os estudiosos e orientalistas que, a partir do século XVIII, trabalharam na região. Um deles foi o pioneiro A. Cunnigham (1871), fundador do Archaeological Survey of India e cujo trabalho esteve voltado ao levantamento sistemá- tico das antigas cidades no noroeste da Índia a partir das fontes clássicas - principalmente na região de Gandhara, separada da Báctria pela cordilheira Hindu Kush (Paropamisos), que permaneceu durante algum tempo sob domínio das dinastias indo-gregas. Outro, foi o próprio M. Aurel Stein $(1928,1929)$ que, a partir do final do século XIX, realizou explorações sistemáticas na Ásia Central.

A menção às milhares de cidades que ocupavam a antiga Báctria, nas fontes clássicas, foi geralmente associada à dominação grega (ver Tarn 1951:118; Leriche 2007: 125-6). No entanto, o trabalho arqueológico empreendido nessa área a partir da década de 1970 revelou, não apenas uma quantidade elevada de assentamentos urbanos em época greco-bactriana, mas também uma ocupação continua e um crescimento urbano intenso, ambos anteriores à passagem de Alexandre e à emergência das cidades do referido periodo. Um dos arqueólogos envolvidos nas pesquisas atuais nessa região chegou mesmo a afirmar que a célebre "terra das mil cidades" se aplicaria melhor à Báctria do periodo kushan, que se seguiu ao greco-bactriano (Leriche 2007: 148). Nesse sentido, a alusão ao grande número de cidades encontrada nas fontes textuais, embora imprecisa

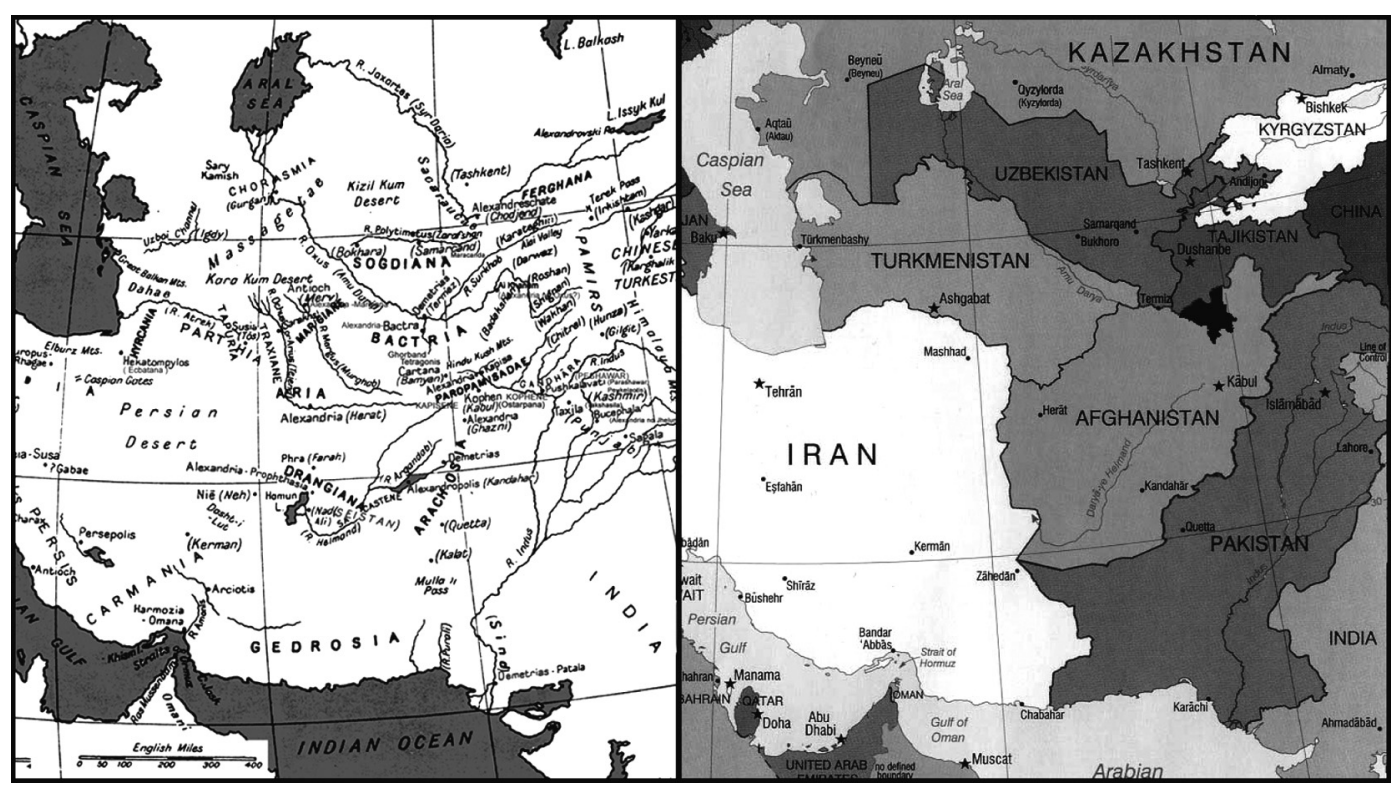

Fig. 1. Mapa geral da Ásia Central com a Báctria (a partir de Tarn 1951: 219) e da divisão geopolitica atual com a área prospectada por Gardin (1998: 218), em destaque, no nordeste do Afeganistão. 
e problemática, foi e continua a ser corroborada pela evidência arqueológica profusa presente na região.

Como observamos em outro artigo (Aldrovandi 2009a), no início dos estudos sobre a Báctria, os pesquisadores desconheciam a existência efetiva de colônias gregas ou da presença concreta do Helenismo nesse território. O próprio Foucher (1942: I, 64-83), antigo diretor da Delegação Arqueológica Francesa no Afeganistão (DAFA), em 1925 e após um ano e meio de pesquisas na região, considerou a possibilidade da existência de um helenismo bactriano uma mera miragem. Anos mais tarde, após a descoberta de um complexo de templos do periodo kushan em Surkh Kotal, no vale afegão do rio Qunduz, o professor Schlumberger, então diretor do DAFA, postulou, em 1951, a existência de uma cidade helenizada na Báctria (Schlumberger 1960). No entanto, foi somente após a descoberta fortuita, em 1964, das ruínas gregas da célebre cidade de Ai-Khanum possivelmente a Alexandria no Oxus (Oxeiana, ver Tarn 1951: 118-19) -, situada na margem afegã do rio Amu Daria (o antigo Oxus), que essa teoria foi efetivamente comprovada (Fig. 2).
As escavações realizadas nessa cidade pelo diretor subsequente do DAFA, o professor $P$. Bernard, foram empreendidas sistematicamente ao longo de dez anos. Um conjunto de edifícios públicos - quarteirões administrativos, mausoléus, templos, ginásio, heroon, teatro, entre outros -, cuja natureza e dimensão atestavam claramente a importância dessa cidade, colocando-a, já nas primeiras etapas de campo, como a provável capital desse amplo território. A metrópole greco-bactriana foi descrita de modo triunfal, sobretudo como "uma pólis grega", o que transformou-a no exemplo favorito "da cultura grega a penetrar e dominar o Oriente” (ver Bernard 1967, 1982, 1994). Por sua vez, um "programa urbano dessa amplitude pressupunha uma região com uma densidade demográfica suficientemente alta”, como observaram Gardin e Lyonnet (1978/79: 99), pesquisadores que implementaram o programa de prospecção bactro-oriental. Os primeiros traços da ocupação da área rural desse território haviam sido observados por Schlumberger, em sua primeira exploração da área, em 1964. Dez anos mais tarde, J. C. Gardin, com o consentimento de Bernard, realizou um estudo sistemático de caráter intensivo dos vestigios de superficie presentes na

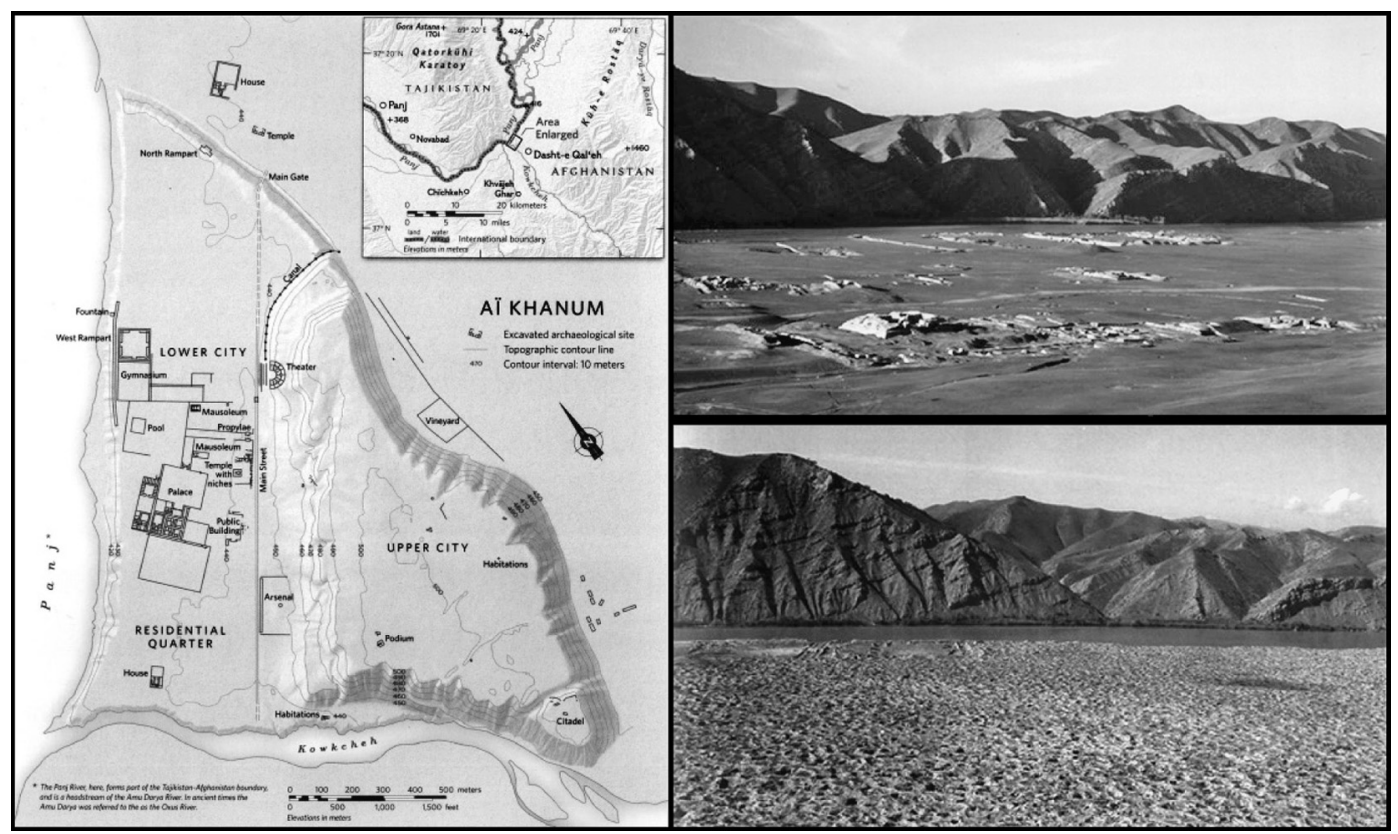

Fig. 2. Planta da cidade de Ai-Khanum (em Heibert e Cambon 2008: 82) e visão do sítio antes e após a devastação das guerras afegãs. 
planície que se estendia ao noroeste do sítio de $\mathrm{Ai}$ Khanum e que formava, segundo esse pesquisador, parte da khóra da grande cidade (ver Gardin e Gentelle 1976, 1979; Gentelle 1978).

Em seguida, foi empreendido um levantamento arqueológico extensivo da região bactrooriental, entre os anos 1974 e 1978, cujos resultados preliminares foram publicados na revista Mesopotamia XIII-XIV (Gardin e Lyonnet 1978-1979). Somente vinte anos mais tarde, Gardin (1998) publicou uma obra definitiva acerca desta série de prospecções, na qual ele apresentou os resultados finais e as conclusões obtidas a partir das campanhas bactro-orientais. Pela primeira vez, foi apresentada uma diacronia da região que pôs em xeque a primazia da ocupação grega, ocupação esta que, após essas e outras descobertas, passou a ser descrita por alguns estudiosos como "apenas um breve evento na história da região" (cf. Rapin 2007: 29). As publicações de Gardin forneceram a principal base de dados para a análise espacial da região bactriana desenvolvida na presente pesquisa, que será apresentada adiante.

Antes disso, no entanto, importa certamente observar que existiu uma dicotomia teórica e, consequentemente, metodológica - muito clara entre a equipe de pesquisadores que escavou a cidade de Ai-Khanum e aquela que realizou o levantamento de superficie na Báctria Oriental. Como observou acertadamente Fussman (1996: 244), não é simplesmente no âmbito formal das publicações que as diferenças nos objetivos cientificos se tornam evidentes - as escavações em Ai-Khanum foram publicados na série de Memórias da Delegação de Arqueologia Francesa no Afeganistão, sob a responsabilidade de Bernard; e os resultados das prospecções, pelo Centro Nacional de Pesquisas Cientificas - CNRS e, mais tarde, renomeados como Memórias da Missão Arqueológica Francesa na Ásia Central, ambas sob direção de Gardin. Enquanto as publicações de Bernard são quase inteiramente dedicadas ao estudo da arquitetura e da arte decorativa da "cidade helenística", o escopo da série de Gardin é muito mais amplo - a Ásia Central -, e não existe exclusividade ou limitações cronológicas, mais que isso, a ênfase esteve focada, principalmente, sobre os periodos não- gregos e não apenas na arte. Embora não haja, necessariamente, um conflito epistemológico entre a Arqueologia Clássica de Bernard - com sua ênfase na arquitetura, arte e história política -, e a chamada Nova Arqueologia, praticada por Gardin, elas não conseguiram ser reconciliadas na região em questão (cf. Fussman 1996: 244-6). As publicações, neste caso, espelham claramente cada uma das metodologias aplicadas.

Os volumes dedicados a Ai-Khanum foram publicados à medida que as escavações se seguiram, em relação ao urbanismo não forneceram um plano sistemático de estudo do traçado das ruas, da função dos espaços vazios, do zoneamento da cidade ou das razões da localização dos edifícios. Não parece haver indício de que um estudo sistemático do planejamento urbano venha a ser publicado, ao menos até o presente, e a única discussão geral sobre a cidade foi feita em um comentário sobre o mapa das escavações de Ai-Khanum (ver Bernard 1981: 110-14). Não houve nenhum estudo detalhado das imagens aéreas, que atualmente poderiam ser suplementadas pelas imagens de satélite. Como observou Fussman (1996: 245), de modo bastante perspicaz, não se forneceram, sequer, hipóteses ou razões demonstrativas do objetivo de construir uma cidade de tal porte naquele local. Nas palavras do pesquisador:

Ninguém vai culpar os arqueólogos por não terem sido capazes de fornecer $\mathrm{o}$ nome grego da cidade, por não terem descoberto nenhuma evidência precisa de sua fundação (se na época de Alexandre ou de Seleucos), nem por não conseguirem afirmar se o palácio foi uma residência real ou apenas um edifício administrativo habitado pelo governador e seus funcionários. (...) Mas nós poderiamos esperar por algum tipo de estudo geopolítico. Em seu lugar, só é fornecido um breve conjunto de afirmações sem confirmação. (...) Ai-Khanum estava localizada em uma posição estratégica e foi utilizada como um posto militar para manter as estradas livres dos inimigos nômades. Ela também adquiriu alguma riqueza "por meio da colonização agrícola 
direta dos cavalheiros-agricultores (gregos)" (Bernard 1974: 102). Depois que o primeiro levantamento da planície de AiKhanum foi realizado por Gardin (....) outro conjunto de explicações foi apresentado (...). A exploração das possibilidades agricolas em um território bem irrigado associada à possibilidade de construir uma grande cidade fortificada em um local conveniente (dois rios e uma acrópole) é, portanto, a melhor explicação (Fussman 1996: 245-6; tradução nossa).

Os problemas em relação às escavações de Ai-Khanum são numerosos. O papel das trocas e do comércio, por exemplo, não foi sequer abordado. Muito pouco, praticamente nada, se sabe sobre os artesãos, os comerciantes, ou os agricultores dessa cidade. Também não há menção sobre a existência de um mercado ou um bazar, muito menos sobre a sua possivel localização. Os próprios mapas produzidos na época da escavação raramente mostram Ai-Khanum inserida em seu território, seja na planície ou em uma porção mais significativa da Báctria (ver Rapin 1992). Neste discurso arqueológico, propugnado por Bernard e sua equipe, a "cidade helenística" e, consequentemente, o "gênio grego" pairam impassiveis e imaculados diante da região que ocuparam, como se tivessem, voluntária ou propositalmente, permanecido livres de qualquer contaminação local. Os relatórios finais não possuem nenhuma narrativa histórica das escavações e, o que certamente é mais grave para as pesquisas, nenhuma cronologia geral. Ocorre que cada um dos autores dos volumes publicados acabou por fornecer uma cronologia própria, o que inevitavelmente incorreu em discrepâncias (ver Francfort 1984: 2-3; Veuve 1987: 100-101; Rapin 1992: 281-94).

Além disso, embora nenhuma evidência especifica sobre um ataque, queima ou saque dos nômades tenha sido encontrada nessa cidade, houve um consenso geral entre os especialistas do DAFA de que a cidade foi abandonada pelos gregos por volta de 145 a.C. e que isto teria ocorrido devido à pressão dos nômades (ver Fussman: 1996: 247). Outro ponto intrigante mantido, intencionalmente ou não, sem esclarecimento pela equipe de Bernard é a existência de uma edificação murada a cerca de $2 \mathrm{~km}$ ao norte da muralha da cidade greco-bactriana - grande o suficiente (25 ha) para ser chamada de "cidade circular” por Gardin (1998: 136), Kohna Qala (47) -, e cujos vestigios cerâmicos remontam ao periodo aquemênida. Fussman (1996: 246), ao discorrer sobre a ocupação, lembrou acertadamente que, caso essa cidade tivesse sido uma capital provincial antes do advento grego, o problema histórico e geopolitigo da localização de AiKhanum deveria ser abordado de um modo totalmente distinto, entretanto, sua presença foi praticamente ignorada nas publicações do DAFA. Como ele mesmo observou, "as escavações em AiKhanum demonstram a verdade do antigo provérbio: você só encontra aquilo que procura" (Fussman 1996: 247).

A razão para abordarmos estas questões não tem, certamente, a intenção de desmerecer o trabalho e o grande valor das escavações empreendidas pela equipe de P. Bernard em AiKhanum. Embora seus resultados estejam focados na história da arte e na historiografia tradicional - algo esperado para a época em que as escavações foram realizadas -, é preciso considerar que sem os dados ali encontrados, saberiamos ainda menos sobre aquela cidade, hoje totalmente devastada pelas sucessivas guerras travadas em território afegão (ver Fig. 2). No entanto, não podemos deixar de considerar os sérios problemas que qualquer pesquisador encontra, quando o ponto de partida para uma pesquisa está, de antemão, fundamentado em paradigmas etnocêntricos. Como observou recentemente Leriche (2007: 130), o impacto e as mudanças ocorridas na Ásia Central durante o periodo de dominação grega não foram tão cruciais se pensados em termos de desenvolvimento e ocupação do território.

Em relação à pesquisa de Gardin, o mesmo tipo de espelhamento mencionado anteriormente, entre as publicações e as aplicações teóricometodológicas, pode ser verificado. Para Fussman (1996: 248), por exemplo, a abordagem focada na Ásia Central implicava em uma mudança nos interesses acadêmicos e denotava uma ruptura temporal com a tradição franco-indiana do DAFA. A própria publicação dos primeiros resultados da prospecção bactro-oriental na revista italiana 
Mesopotamia pode ser observada como um indício dessa ruptura e de uma abertura para novas questões cuja ênfase, a partir de então, passou a ser a entidade geográfica, cultural e geopolitica. Nessa nova sistemática, em que os levantamentos de superfície seguiam inicialmente uma tendência estabelecida pelos arqueólogos soviéticos, os objetivos cientificos, a metodologia e as hipóteses epistemológicas aparecem claramente expostas nas primeiras páginas dos relatórios. As questões históricas que Gardin e sua equipe abordaram referiam-se à demografia da região e às razões ecológicas, econômicas e geográficas que estavam por trás dos assentamentos ali existentes e, portanto, às modificações da paisagem bactriana e às mudanças populacionais. Nesse sentido, não havia mais uma preponderância tipológica de determinados artefatos em detrimento de outros, como se observa nas publicações do DAFA, pois na Nova Arqueologia, "um caco pode nos dizer mais que uma longa inscrição" (Fussman 1996: 249). Tais questões passaram, portanto, a estar inseridas em uma diacronia de longa duração, sem um limite cronológico preestabelecido e, justamente por isso, sem um periodo histórico preponderante - como o Helenismo do DAFA -, em detrimento dos demais.

Apesar do trabalho vultoso empreendido, chama atenção, ao mesmo tempo, um certo pessimismo interpretativo que permeia as discussões ao longo de toda a publicação final de Gardin (1998) e que revela uma aparente desesperança diante do registro material, algo que, por sua vez, remete aos caminhos trilhados pela Arqueologia após a tomada de consciência em relação aos limites da pesquisa arqueológica - a perda da inocência em Clarke (1973). Os resultados dessa nova auto-critica desencadearam, como bem observou Bradley (1993), por um lado, um tecnicismo extremado dos métodos cientificos e, por outro, uma discussão teórica distante dos dados propriamente ditos, quase mera retórica. Desta polarização decorreu um crescente desencantamento com o registro arqueológico e uma postura muitas vezes defensiva frente a aparente impossibilidade de seguir adiante nas interpretações, algo perspicazmente descrito por Bradley (1993:132) como: "uma auto-consciência critica tão aguda que exaure a criatividade individual". Essas questões serão retomadas adiante.

\section{O levantamento arqueológico da Báctria oriental}

As prospecções na região bactro-oriental realizadas pela equipe de Gardin contaram com duas etapas principais. Os resultados da primeira etapa, conduzida entre 1974 e 1976 na região ao redor de Ai-Khanum, revelaram os vestigios de uma exploração intensiva do solo no periodo greco-bactriano, baseada em um amplo sistema de irrigação e em um programa regional de gerenciamento de terras. Assim, no início das investigações, a opinião dos investigadores era a de que o desenvolvimento dessa área estivera diretamente associado ao que eles consideravam ser o "expertise da engenharia militar grega e do gênio grego" (Gardin e Gentelle 1979: 15). No entanto, um dado importante revelado pelo levantamento foi de que a concepção do sistema de irrigação ali presente remontava a uma época muito mais antiga - talvez à Idade do Bronze, na segunda metade do terceiro milênio a.C., e, certamente, ao primeiro milênio a.C., época em que o território já possuía uma população densa e era utilizado de modo intensivo. Diferente do que se pensava, a história da planície de Ai-Khanum (Dasht-i Qala) ${ }^{3}$ não se limitou ao periodo de atividade da cidade greco-bactriana (ver Gardin e Lyonet 1978/79: 101; Francfort 1989: 57-58) e essa hipótese precisou ser revista. Como observaram os próprios pesquisadores na publicação preliminar, "os colonos gregos não foram pioneiros em terra virgem" (Gardin e Lyonnet 1978/79: 132) e a época de ocupação greco-bactriana foi marcada, isto sim, por uma intensificação de padrões preexistentes, mas que, ainda assim, permanecia descrita como "o periodo mais próspero de sua história” (Gardin e Gentelle 1979: 9). Enquanto a fundação de Ai-Khanum foi

(3) Também conhecida como planície de Turghaï Tepe; Nowabad; Shortugaï; e de Ai-Khanum (ver Gentele 1978). Como observou Gardin (1998: 39), a planície foi inicialmente nomeada pelos pesquisadores como "Planície de AiKhanum", mas após a análise mais aprofundada da subregião, esse arqueólogo optou por uma nomenclatura menos contestável. Dasht-i Qala é uma das cidades atuais mais importantes da planicie e provavelmente a mais populosa, assim, foi adotada como referência na publicação final. 
considerada a "responsável por estimular muito o aumento da atividade" (Gardin e Gentelle 1979: 18-19).

Um segundo programa extensivo de prospecção, cujo intuito foi recuperar as fases de ocupação regional e favorecer sua interpretação histórica, foi aprovado pelo governo afegão em 1976 e seguiram-se, então, duas campanhas - realizadas em 1977 e 1978, com outras duas previstas para 1979 e 1980 (Gardin e Lyonet 1978/79: 102). Os critérios para a escolha do território a ser sistematicamente prospectado se basearam nas zonas em que a agricultura intensiva parecia mais viável. Assim, a região do levantamento incluiu toda porção geográfica entre o baixo rio Kunduz e o curso médio do rio Kokcha. Essas são as principais áreas cultivadas na Báctria oriental na atualidade, que correspondem ao território afegão irrigado pelas águas de três de seus rios principais: ao norte, o Amu Darya (antigo Oxus); a bacia do Taluqan-Khanabad-Kunduz, ao sul e oeste; e o Kokcha, a leste. Ao norte, o limite estabelecido para o levantamento foi o próprio rio Amu Darya, por razões politicas bastante claras - a fronteira da, então, União Soviética. No entanto, para evitar qualquer anacronismo em relação às fronteiras da antiga Báctria, os pesquisadores lembram que "esse rio não era uma barreira 'natural', no sentido de que as entidades geo-históricas pesquisadas se estendiam de um lado a outro do Oxus e não apenas na margem esquerda, como a fronteira afegã atual” (Gardin e Lyonet, 1978/79: 103). Ao sul, esses limites abrangiam as regiões irrigadas pelo Baixo Kunduz e seus afluentes. Dessa forma, as fronteiras da prospecção coincidiram com os obstáculos físicos para a agricultura, a saber: de um lado as áreas de planície (ao longo dos grandes rios Amu Darya, Kokcha, Taluqan, Khanabad e Kunduz) e, de outro, as áreas montanhosas (Badakhshan). Todas elas separadas, umas das outras, por zonas áridas e de relevo geralmente acidentado.

\section{O método de prospecção}

Em relação à metodologia, a pesquisa foi iniciada pela recuperação dos canais hídricos, de modo a reconstituir a planta dos antigos sistemas de irrigação utilizados na planície de Dasht-i Qala (Ai-Khanum) em todas as épocas de ocupação. Ao mesmo tempo, foram levantadas as tepes - cidades -, situadas nas vizinhanças de cada canal encontradas por meio da coleta de fragmentos cerâmicos, em número suficiente para estabelecer a datação dos canais e dos assentamentos. O objetivo dos pesquisadores era obter uma imagem do território irrigado em cada periodo distinto - da Idade do Bronze ao advento Islâmico (Gardin e Lyonet 1978/79: 104-108) -, i.e., uma perspectiva diacrônica da ocupação bactro-oriental. Assim, os métodos de trabalho foram centrados em três planos: a reconstituição do traçado dos canais; o inventário dos sitios; e a pesquisa dos limites das ocupações. Em razão de a maioria dos sitios arqueológicos encontrados durante a prospecção ser composta por assentamentos destituídos de vestígios arquitetônicos que pudessem fornecer uma cronologia, a cerâmica foi a base fundamental para a reconstrução histórica da região (Gardin e Lyonet 1978/79: 120; Lyonnet 1997; Gardin 1998).

Os resultados dos dois levantamentos empreendidos pelos arqueólogos franceses um intensivo, na planície de Dasht-i Qala (200 $\mathrm{km}^{2}$ ), e outro extensivo, no restante da região bactro-oriental $\left(1500 \mathrm{~km}^{2}\right)$-, evidenciaram um total de 350 e 474 sitios, respectivamente (cf. Gardin 1998: 14). Vale observar que a publicação final das campanhas de prospecção empreendidas por Gardin (1998) apresentou uma modificação na divisão da área prospectada pois as 10 sub-regiões inicialmente levantadas e discutidas na publicação inicial (Gardin e Lyonnet 1978/79) aparecem, depois, redistribuidas em 19 sub-áreas (Gardin 1998: 17). Essas 19 subregiões (Fig. 3) e os assentamentos associados foram apresentados em novas plantas, nas quais se encontram os esboços dos canais de irrigação descritos por Gentelle (1989). Entretanto, não fica realmente claro o motivo efetivo dessa nova sub-divisão. Em sua obra final, o pesquisador também incorporou dados cronológicos mais detalhados propostos por Lyonnet (1997), que estabeleceu uma cronologia cerâmica para a Ásia Central, ampliando os horizontes diacrônicos da ocupação da região bactro-oriental. 


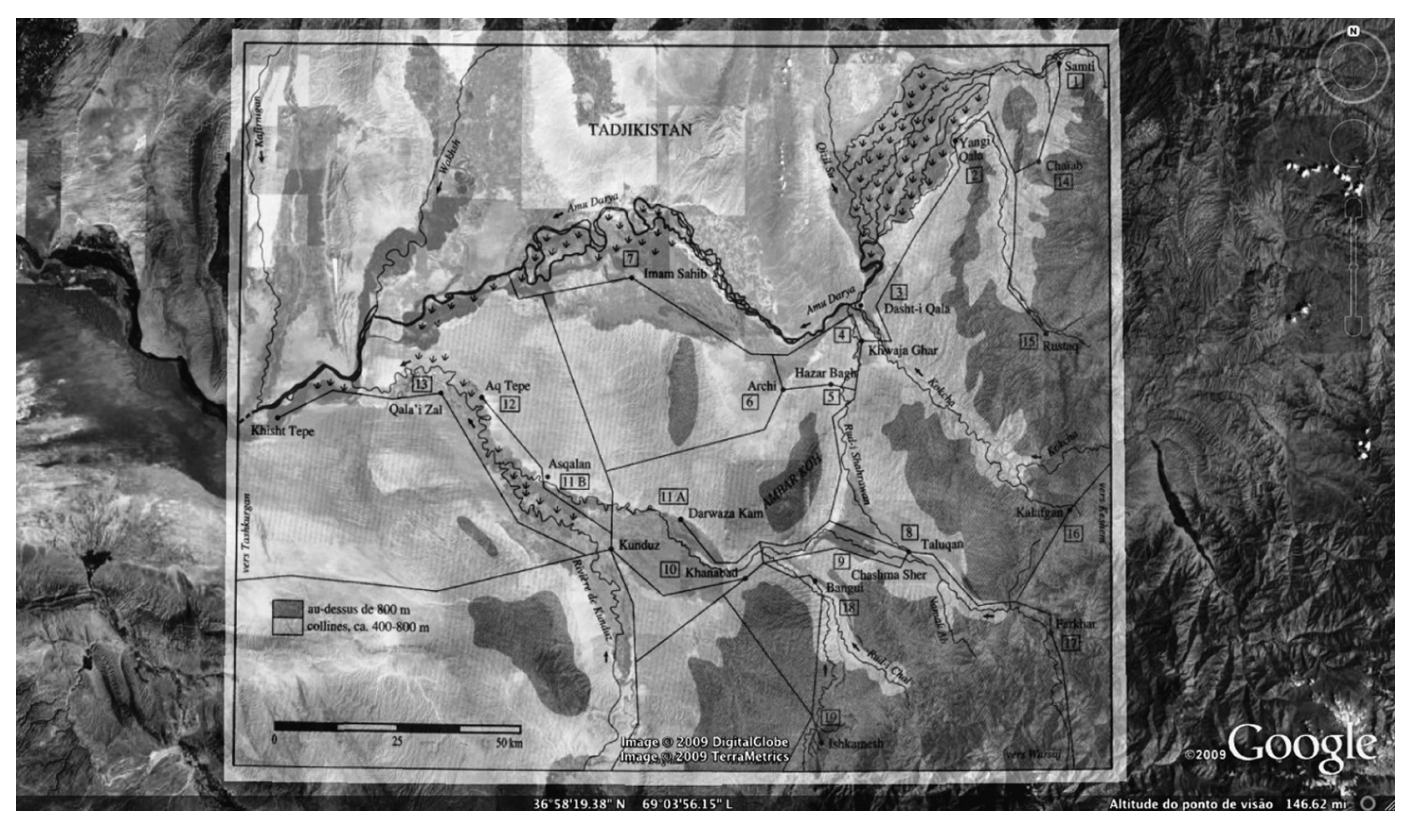

Fig. 3. Mapa da divisão do território prospectado em 19 sub-regiões (Gardin 1998: 219) inserido sobre a imagem de satélite (Fonte: (C) Google Earth 36 58'19.38"N; 69 03'56.15"E).

Essas 19 sub-regiões são apresentadas por Gardin (1998: 18) em uma tabela, na qual aparecem associadas aos antigos canais de irrigação. A partir disso e da descrição detalhada de cada um dos sitios presentes nas 19 sub-regiões, fornecidas por Gardin (1998: 35-101), foi elaborada uma sintese quantitativa de cada uma das regiões prospectadas. Por questão de espaço, apresentamos apenas as quantidades totais dos sitios das regiões e sub-regiões em uma mesma tabela (Fig. 4).

\section{A Cronologia}

Gardin (1998: 20) forneceu também um quadro cronológico da região, apresentado abaixo (Fig. 5) e complementado pelas siglas que utilizamos na análise quantitativa que será apresentada adiante.

Na publicação preliminar, os pesquisadores haviam estabelecido uma periodização mais restrita, cuja divisão abrangia apenas 5 periodos (Gardin e Lyonet 1978/79: 108). ${ }^{4}$ Em sua

(4) Sendo eles: 1. Idade do Bronze (B), que correspondia aos sítios até o segundo milênio a.C.; 2. Época "Pré- publicação final, Gardin (1998: 105-123) propôs uma cronologia mais detalhada que se estendeu do Calcolítico até o advento do Islamismo. Observamos, porém, que a presente análise se limitou a discutir esse recorte cronológico somente entre a Idade do Bronze (IB) e o periodo da ocupação Kushan (KH). O recorte cronológico adotado na publicação final de Gardin (1998: 28) e aquele abrangido nesta pesquisa aparecem representados na diacronia apresentada na Fig. 6.

Helenística" (P), um denominação que englobava não apenas o periodo Aquemênida na Ásia Central (VI- IV a.C.), como também o periodo imediatamente anterior, no qual teria ocorrido o chamado "renascimento" da irrigação, constatado na Báctria oriental durante o primeiro milênio; 3. Periodo Greco-Bactriano $(G)$, que possui uma cronologia detalhada graças à cerâmica de $\mathrm{Ai}$ Khanum, mas que foi tratado pela prospecção como um único periodo; 4. Periodo Kushan e Pós-Kushan (K), considerados em conjunto (entre os século I e IV d.C.), bem como após as invasões heftalitas (V e VI d.C.); e, finalmente, 5. Periodo Islâmico (I), a partir da formação dos primeiros grandes estados islâmicos na Ásia Central (VII - VIII d.C.). 


\begin{tabular}{llc}
\hline \multicolumn{1}{c}{ Região } & \multicolumn{1}{c}{ Número e nome das sub-regiões } & $\begin{array}{c}\text { Número de sítios } \\
\text { prospectados }^{5}\end{array}$ \\
\hline \hline Margem esquerda & 1 Samti & $\mathrm{T}=6$ \\
do Amu Darya & 2 Yangi Qala, norte e sul & $\mathrm{T}=16$ \\
& 3 Dasht-i Qala & $\mathrm{T}=350$ \\
& 4 Khwaja Ghar & $\mathrm{T}=13$ \\
& 5 Hazar Bagh & $\mathrm{T}=18$ \\
6 Archi, planície, planaltos a leste e piemonte sul & $\mathrm{T}=71$ \\
Margens dos rios & 7 Imam Sahib & $\mathrm{T}=46$ \\
Taluqan, & 8 Taluqan & $\mathrm{T}=62$ \\
Khanabad e & 9 Chashma Sher & $\mathrm{T}=13$ \\
Kunduz & 10 Khanabad - Kunduz, margem esquerda, planaltos sul & $\mathrm{T}=64$ \\
& 11 Khanabad - Kunduz, margem direita & $\mathrm{T}=13$ \\
Montanhas & 12 Baixo-Kunduz, margem direita & $\mathrm{T}=3$ \\
doBadakhshan & 13 Baixo-Kunduz, margem esquerda & $\mathrm{T}=3$ \\
& 14 Chaïab & $\mathrm{T}=5$ \\
& 15 Rustaq & $\mathrm{T}=27$ \\
& 16 Kalafgan & $\mathrm{T}=25$ \\
& 18 Banghar & $\mathrm{T}=21$ \\
& 19 Ishkamesh & $\mathrm{T}=17$ \\
& & $\mathrm{~T}=36$ \\
\hline
\end{tabular}

Fig. 4. Tabela das regiões e sub-regiões prospectadas com a totalização dos sitios a partir de Gardin (1998: 18).

\section{Breve histórico da ocupação bactro-oriental}

A Báctria tem uma história extremamente longa e complexa envolvendo uma quantidade vultosa de informação. Assim, apresentamos aqui apenas um histórico bastante abreviado dos principais elementos que fornecem um referencial direto para nossa pesquisa (ver Fig. 7). Embora toda a discussão de Gardin (1978/ $79,1998)$ tenha se focado na irrigação como o motor propulsor do desenvolvimento da Báctria Oriental - algo que já havia sido constatado por Allchin (1957: 138) -, os primórdios da agricultura seca e da pecuária foram atestados na Ásia Central muito antes do surgimento dos primeiros canais de irrigação (ver Sarianidi 1992). Na Báctria, em particular, foi nas colinas que cercam a planície tadjiqueafegã que se encontraram as primeiras ocupações fundadas nesse tipo de economia durante o Neolitico (Fédorov-Davydov 1985:174-75). Existem duas hipóteses principais que tentam explicar o povoamento da Báctria antes do desenvolvimento da irrigação. Uma delas propõe uma ocupação mais antiga da região, datada do quarto milênio, enquanto a outra defende a ideia de um desenvolvimento relativamente tardio do complexo bactromargiano, que teria permanecido praticamente desabitado até c. 2200 a.C. (cf. Gardin 1998: 158-59).

\subsection{O Calcolítico (C) e Bronze Antigo}

As atribuições cronológicas mais antigas encontradas pela equipe de Gardin (1998: 107) referem-se a alguns sitios na região do Taluqan (sub-região 8), cujos fragmentos cerâmicos supostamente remontam à primeira metade do terceiro milênio a.C. Embora tenha preferido se abster quanto à formulação

(5) Neste artigo, não constam os números de cada sitio, nem sua tipologia (ex.: $\dagger=$ sítio com cemitério; $\Delta=$ fortaleza), nem os períodos cronológicos abrangidos. As tabelas completas desse detalhamento, realizadas durante esta pesquisa, estão disponiveis para consulta com a autora. 


\begin{tabular}{lcc}
\hline \multicolumn{1}{c}{$\begin{array}{c}\text { Periodização base } \\
\text { (Lyonnet 1997: 35) }\end{array}$} & $\begin{array}{c}\text { Siglas em } \\
\text { Gardin (1998) }\end{array}$ & $\begin{array}{c}\text { Siglas da } \\
\text { Quantificação }\end{array}$ \\
\hline \hline Calcolitico e Bronze antigo (c. 3500-2500 a.C.) & Periodo C & C \\
Bronze médio (c. 2500-1500 a.C.) & Período B & IB \\
Fase I - Fase II & Fase B1 & IB1 \\
Fase III a - Fase III b & Fase B2 & IB2 \\
Final do Bronze, início do Ferro e período Persa (c. 1500-330 a.C.) & Período P & AQ $^{6}$ \\
Fase I & & \\
Fase II & Fase P 1 & AQ1 \\
Fase III & Fase P 2 & AQ2 \\
Período Helenístico (330-145 a.C.) & & \\
Invasões nômades (de 145 a.C. até início do século I d.C.) & & GB \\
Período Kushan (séculos I a.C. ao VI d.C.) & Período G & Período G/K \\
Fase Yueh-chi /Kushan e primeira etapa dos Grandes Kushan & Período K & KH \\
Segunda etapa dos Grande Kushan, fase kushanosassânida e/ou pós-Kushan & Fase K 1 & KH1 \\
Periodo Heftalo-Turco (séculos V à metade do VIII d.C.) & Fase K 2 & KH2 \\
Fase I: Chionitas, Kidatitas, Heftalitas & Periodo H & HF \\
Fase II: Turcos & Fase H 1 & HF1 \\
Periodo Islâmico, (não abrangido em Lyonnet 1997): & Fase H 2 & HF2 \\
Pré-Timurida (séculos IX ao XIV d.C.) & Período I & IS \\
Timurida e Pós-Timurida (séculos XV ao XIX d.C.) & Fase I 1 & IS1 \\
\hline
\end{tabular}

Fig. 5. Quadro cronológico estabelecido a partir da periodização cerâmica (em Gardin 1998: 20) e cujas fases abordadas nesta pesquisa encontram-se em destaque.

\begin{tabular}{|c|c|c|c|c|c|c|c|c|c|c|c|c|c|}
\hline & 2500 & & 1500 & & 330 & 145 & 0 & & 500 & & 750 & 1200 & 600 \\
\hline & IB1 & & AQ1 & & & GB & KH1 & & HF1 & & IS1 & & \\
\hline C & & IB2 & & AQ2 & GB & $\begin{array}{c}\text { ' } \\
\mathrm{KH}\end{array}$ & & $\mathrm{KH} 2$ & & HF2 & & IS2 & IS3 \\
\hline
\end{tabular}

Fig. 6. Recorte cronológico adaptado a partir de Gardin (1998: 28) com os periodos aqui pesquisados em destaque.

de uma hipótese sobre as circunstâncias que permitiram o desenvolvimento da agricultura irrigada na região durante o Bronze Antigo, esse pesquisador encontrou, ali, elementos extremamente importantes: o primeiro foi a própria existência de uma ocupação que remontava a esse periodo recuado, até então desconhecida nessa área da Báctria; o outro diz respeito ao modo como ela ocorreu, no caso particular de Taluqan, anunciando um savoir-faire na questão da irrigação considerado surpreendente pelo pesquisador, "já se delineia,
(6) Dividido em duas fases (ver Gardin 1998: 144, n. 23), uma anterior aos aquemênidas, demoninada P1 pelo pesquisador e, aqui, chamada AQ1; e uma posterior (P2), propriamente persa aquemênida, aqui chamada $A Q 2$. A denominação $\mathrm{P}$, não se referia originalmente ao periodo Persa e, sim, à terminologia "Pré-Helenística", estabelecida pelos pesquisadores anteriormente (ver Gardin e Lyonnet 1978/79: $124,132-37$ ), o que consideramos demasiado tendenciosa e, portanto, inadequada, por esta razão, haviamos preferido utilizar AQ, antes mesmo de termos a publicação final em mãos. Essa terminologia atribuia uma ênfase claramente maior ao periodo greco-bactriano que, por sua vez, desvalorizava a importância dos periodos anteriores - como uma espécie de longa e vagarosa "pré-paração" para o "advento grego" - uma vez que, somados, em um ou mesmo dois subperiodos (P; P1 e P2), eles abrangem cerca de um milênio. 


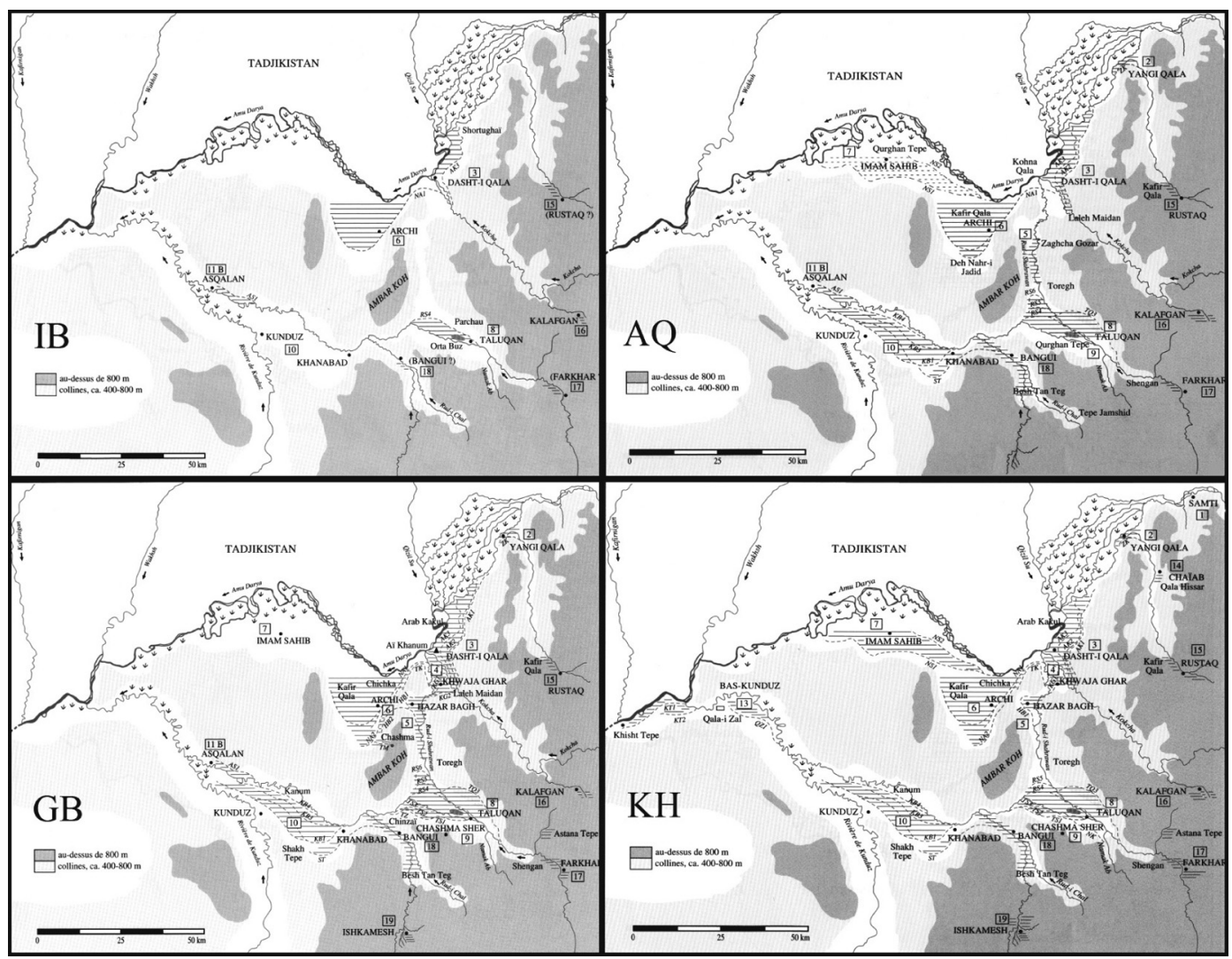

Fig. 7. Mapas das regiões ocupadas durante os periodos IB, AQ, GB e KH respectivamente (a partir de Gardin 1998: 220-23).

naquela época, o princípio diretor de irrigação artificial na região durante todas os periodos subsequentes" (Gardin 1998: 107).

\subsection{Idade do Bronze (IB)}

Os vestigios da irrigação no periodo $\mathrm{IB}$, que se estendeu entre 2500 e 1500 a.C., na mesma planície do Taluqan sugerem uma continuidade do esquema precedente. Além disso, surgiram ocupações em outras subregiões, como a planície de Dasht-i Qala que apresentou um sistema de irrigação de caráter verdadeiramente monumental, evidenciado em Shortugaï, uma cidade proto-histórica da Civilização do Vale do Indo, na margem do Oxus (Franckfort 1989). A constatação de que os fragmentos cerâmicos do Vale do Indo foram fabricados na própria sub-região de Dasht-i Qala (Lyonnet 1997), inseriu essa área numa perspectiva muito mais ampla. Considerada um centro comercial, Shortugaï fornecia ouro, cobre e o lápis-lazúli das minas do Badakhshan às distantes cidades do Vale do Indo (Kenoyer 1998: 96). Uma das razões sugeridas por Gardin (1998: 108) para explicar o desenvolvimento da região foi a multiplicação das comunidades agrícolas no terceiro milênio, devido à maestria sobre as técnicas de irrigação artificial por gravidade. A hierarquia entre os sítios e a presença dos assentamentos fortificados caracterizariam, segundo esse pesquisador, "mais ou menos um processo de urbanização" (Gardin 1998: 108).

Vemos aqui, mais uma vez, uma discussão pautada por uma visão etnocêntrica, pois Shortugaï é, comprovadamente, um sítio pertencente à rede de centenas de cidades da Civilização do Vale do Indo (ou Harappan) -, parte de uma constelação de unidades 
sociopoliticas e de um processo efetivo de urbanização conhecido por representar o periodo da Primeira Urbanização da Índia antiga. $O$ próprio Gardin evidenciou fragmentos cerâmicos do Vale do Indo na superfície de outros sítios próximos a Shortugaï. Ele também observou que o grau de complexidade das sociedades antigas está diretamente relacionado à questão das comunicações e das trocas de longa distância. A divisão instrumental do periodo (IB1 e IB2) foi considerada frágil pelo próprio pesquisador. Mas serviu para assinalar a ascensão do povoamento e da irrigação, caracteristica da fase IB1, nas planícies de Dasht-i Qala, Taluqan e Asqalan $(3,8,11)$; e os sinais de recuo notados nessas mesmas áreas, na fase IB2, na chamada "crise do segundo milênio" (Francfort 1898: 96-103).

A escavação de Shortugaï evidenciou atividades artesanais e comerciais suficientes para supor um nivel de organização mais elevado que aquele das comunidades estritamente agrícolas. Gardin (1998: 155) recorreu à hipótese das chefias (unidades sociopoliticas múltiplas) com autoridade forte o suficiente para orquestrar a politica hidro-agricola de cada sub-região. Essas seriam as formas de organização proto-estatais na Ásia Central que já existiam no início da Idade do Ferro. Tais ocupações foram evidenciadas no complexo bactro-margiano como possiveis centros de organização politica, mas, na Báctria Oriental, os sítios IB são mais modestos, o que faz supor um enclave regional, subordinado a uma autoridade politica maior. De modo geral, ainda não há como avaliar o grau de interação politica da Ásia Central ao longo dos séculos que precederam a conquista persa. Gardin (1998: 156), seguindo aquilo que Allchin (1957: 134) havia verificado anteriormente, recorreu à uniformidade cerâmica encontrada entre a Corasmia e a região dos Pamir, a partir da qual seria possivel inferir uma relação estreita entre as regiões desse vasto território, mas não necessariamente como prova da existência de uma federação política ou de uma entidade proto-estatal hipotética.

\subsection{Final da Idade do Bronze, início do Ferro (AQ1) e o Período aquemênida (AQ2)}

Periodo que perpassa mais de um milênio - entre 1500 e 330 a.C. A expansão da agricultura irrigada é um dos traços principais da época, quando passa a recobrir a quase totalidade das superfícies disponiveis, inclusive algumas áreas montanhosas. Ocorre, no entanto, de forma distinta em cada sub-região, sem refletir um crescimento contínuo ou equilibrado entre a Idade do Bronze e as conquistas persa e grega. No início da Idade do Ferro, a Ásia Central esteve envolta pelas migrações e uma interação continua entre populações nômades e sedentárias. A multiplicação de sítios fortificados nesse periodo é uma particularidade que merece atenção, embora existam dúvidas em relação à época de construção dos mesmos, pois, como vimos, já existiam fortificações no periodo anterior IB (ver Gardin 1998: 110) e sua recorrência é verificada na Ásia Central como um todo (ver Francfort 1979, 1994: 276-278; Askarov 1992: 451-453).

Independentemente de as mudanças observadas com o advento do uso do ferro estarem ou não relacionadas à chegada de povos falantes de indo-ariano - algo que não é passivel de comprovação (Allchin 1957; Franckfort 1989; Lyonnet 1997; Gardin 1998) -, uma mudança profunda na sociedade bactro-oriental está arqueologicamente atestada tanto pelo novo padrão de assentamentos (Allchin 1957: 134; Abetekov e Yusupov 1994: 25-6), quanto pelo progresso da irrigação artificial ocorrido durante esse periodo. As evidências cerâmicas indicam a presença de três elementos inquestionáveis: de uma parte, a infiltração de povos nômades ou pastoris das estepes eurasianas e a consequente sedentarização de parte dessas populações, primeiro no campo, depois nas cidades; isso teria sido acompanhado de um movimento de migração de populações indo-arianas, considerado uma osmose entre nômades e sedentários da região; além disso, haveria também movimentos internos na própria região, entre as planícies cultivadas e a áreas montanhosas do Badakhshan, dos povos nômades (Gardin 1998: 159-160) 
O final desse longo periodo assistiu à ascensão da dominação persa na Ásia Central, durante a qual parece ter sido mantida uma simbiose nomádico-sedentária, de origem IB, sobre a qual se formou a cultura de época propriamente persa. A Báctria - Báxtris aparece na inscrição de Behistun, de 518 a.C., entre as 23 regiões sob dominio persa, mas sua existência como estado independente possivelmente remontasse ao século IX a.C. (ver Abetekov e Yusupov 1994: 32; Dandamayev 1994: 35-8). A análise de fontes textuais assírias, persas e greco-latinas, realizada por Briant (1984), estabeleceu que o desenvolvimento mais expressivo da região teria ocorrido durante a dominação persa. Além da região bactro-oriental, uma série de assentamentos de época aquemênida foram documentados e escavados no norte e centro da Báctria (ver Leriche 2007: 128-29). A construção de assentamentos fortificados nas fronteiras, durante o periodo aquemênida, é mencionada nas fontes clássicas (ver Dandamayev 1994: 4041). No entanto, a revisão detalhada dos dados arqueológicos provenientes da região bactrooriental não confirmou a tese de Briant (1984). A conclusão geral indica ser impossivel concentrar o desenvolvimento regional somente na fase AQ2, pois o conjunto de transformações teria se estendido por todo o periodo AQ (Gardin 1998: 112).

Assim, a entrada dessa região na esfera de influência do Império Aquemênida teve, certamente, consequências profundas no curso de seu desenvolvimento, embora as observações precedentes sobre os periodos IB e AQ1 demonstrem que as grandes linhas desse desenvolvimento já estavam traçadas antes de os sátrapas e seus sucessores gregos tomarem conta da administração regional. A continuidade coerente dos programas de irrigação faz pensar em uma certa permanência das estruturas sociais e econômicas locais, subordinadas a uma autoridade estrangeira que logo descobriu as vantagens de sua manutenção. Ao que tudo indica, a conquista persa não significou necessariamente o fim da relativa autonomia politico-administrativa bactriana mas, sim, sua reorganização e inserção em um sistema estável de governo - as satrapias -, aparentemente sem um caráter intervencionista (Leriche 2007: 148), mas que tornou o contato entre as diferentes regiões sob seu poder, mais regular (ver Allchin 1957: 134-35; Dandamayev 1994: 42-46; Briant 1996: 423).

\subsection{Período greco-bactriano (GB)}

O periodo GB abrange menos de dois séculos de ocupação, entre 330 e 150/130 a.C., um corte relativamente curto na escala cronológica geral da região. Após ser anexada ao império de Alexandre, a Báctria fez parte da politica de ocupação greco-macedônica que consistia em fundar ou refundar cidades - a maioria delas nomeadas ou renomeadas com o próprio nome do imperador (ver Dani e Bernard 1994: 70-2; Bernard 1994: 108-10) em solo anteriormente persa. $\mathrm{O}$ evento mais conhecido sobre a ocupação da Báctria no periodo greco-bactriano foi, como vimos, a fundação da pólis de Ai-Khanum, acompanhada pela formação de uma área de subúrbios e de uma khóra em direção ao interior da planície e ao longo do Amu Darya. Por um lado, o número elevado de sítios GB levantados em Dasht-i Qala, se comparado às demais subregiões, se deve em grande parte ao caráter intensivo da prospecção realizada nessa subregião (Gardin 1998: 111). Embora o pesquisador tenha atribuido o fenômeno de desenvolvimento urbano nessa sub-região à "competência de seus promotores - os gregos - e ao vigor de sua politica agricola" (Gardin 1998: 112), a sequência da prospecção ao invés de corroborar a "superioridade do gênio grego", acabou por mudar essa visão: ela convenceu os pesquisadores de que o esquema grego-bactriano de irrigação e de povoamento da planície em questão perpetuou, em essência, o esquema aquemênida - os mesmos canais principais de irrigação, a mesma concentração relativa de áreas de habitação. Vale notar também que, como vimos, a própria evidência associada à irrigação em época $A Q$ remontava à Idade do Bronze, como atestado em Shortugaï. Ao norte do Amu Daria, Leriche (2007: 133, 140, 147) observou que a dominação greco-bactriana foi 
caracterizada por projetos construtivos e edifícios de tamanho limitado, na maior parte, de phrouria posicionadas de modo a permitir a vigilância de locais de passagem, isto é, de caráter primariamente defensivo.

A explicação geral do fenômeno constituído pela cidade de Ai-Khanum, descrita como um "pólo de atração" para as regiões vizinhas, poderia ser atestada pelo fato de as sub-regiões mais próximas terem crescido, enquanto as mais distantes teriam sofrido uma retração, no entanto, Gardin (1998: 113) preferiu renunciar a essa explicação. Isto porque o "recuo" - mensurado pela raridade relativa de fragmentos cerâmicos $\mathrm{GB}$, se comparados ao conjunto de fragmentos $A Q$-, segundo esse pesquisador, não significaria necessariamente um declínio da ocupação, uma vez que o periodo AQ teria durado aproximadamente um milênio, enquanto o GB apenas cerca de 150 anos e, assim, o número de fragmentos abandonados em cada época de ocupação visivelmente não teria o mesmo peso. Além disso, outros indícios fazem crer que, em certas sub-regiões, a agricultura irrigada se manteve em época GB no mesmo nivel que anteriormente, permanecendo plenamente exploradas. Nesse sentido, a hipótese de uma deserção, mesmo que relativa, das terras baixas vizinhas seria improvável, pois o desenvolvimento intensivo constatado na khóra de Ai-Khanum seria um traço que parece caracterizar todos as grandes sub-áreas da Báctria oriental em época GB, com uma provável exceção em Imam Sahib (7). As áreas montanhosas a leste seguiram esse movimento, com novas ocupações que se conjugaram àquelas preexistentes. Assim, o traço mais importante do periodo GB teria sido o planejamento de traçados de irrigação em áreas mais dificeis, embora esses planos não fossem inéditos. $\mathrm{O}$ crescimento das áreas irrigadas nesse periodo correspondeu a $10 \%$ do total e esteve associado às áreas de piemonte (cf. Leriche 2007: 131). Além disso, a atividade desses novos canais foi de curta duração e não persistiu em época kushan. Gardin não utilizou os horizontes cerâmicos de Ai-Khanum como parâmetro cronológico e, portanto, não houve como reconhecer as eventuais etapas de ocupação da região nesse periodo.
Em suma, embora o povoamento gregobactriano na Báctria oriental se manifeste claramente sobre um plano urbano, o mesmo não pode ser dito sobre seu território, onde o crescimento das áreas cultivadas pode ser interpretado como consequência de uma politica de desenvolvimento hidro-agrícola conhecida e praticada muito antes da chegada dos gregos.

\subsection{Período greco-kushan ( $G B / K H)$}

O periodo seguinte, foi marcado por uma mudança considerável no povoamento da Báctria, desencadeada pelo deslocamento e a chegada de povos nômades durante o dominio greco-bactriano na região, entre 150 a.C. e o início do século I d.C. Em sua publicação final, Gardin (1998:162) preferiu analisar esse encontro dos dois periodos (GB e $\mathrm{KH}$ ), de maneira conjunta, entretanto, os fragmentos atribuidos ao periodo das invasões ou das conquistas nômades (Tarn 1951: 270) - entre a destruição do reino GB e a solidificação do Império Kushan - são muito raros para legitimar qualquer inferência a partir de sua distribuição (Gardin 1998: 114). Na época em que esse corpus, limitado a três tipos cerâmicos, aparece, a cerâmica GB continuava a ser produzida. Embora reduzido, ele foi interpretado como indício de um declínio considerável da região nessa época (Lyonnet 1997: 169), mas a ausência desses fragmentos em outras subregiões, não significou que elas tenham sido "abandonadas". Nenhum sitio prospectado por Gardin (1998) foi atribuido propriamente a esse periodo (ver Fig. 8).

\subsection{Período kushan (KH)}

O movimento das populações nômades das estepes ao norte do território conquistado pelos gregos foi evidenciado pela cerâmica e atestado pela estratigrafia de dois sitios escavados: AiKhanum e Bactra (ver Rapin 2007). A prospecção de Gardin (1998) evidenciou o horizonte cerâmico do periodo $\mathrm{KH}$, com uma tipologia bastante diversificada e distribuida por todo o território, que revelou algumas diferenças 
significativas entre os esquemas de ocupação do solo em comparação com o periodo anterior. Gardin (1998: 163) acredita que a hipótese mais provável não é a da sedentarização de povos nômades, mas da chegada de povos que já praticavam a agricultura. Os estados poderosos que os Yuen-chi fundaram ao longo do caminho que percorreram até chegar à região em questão e a relativa rapidez de sua emergência exigem, por si sós, uma revisão da imagem de conquistadores nômades da Báctria. Holt (1988: 54-59) já havia sugerido uma relação simbiótica forte entre os povos das estepes e os sedentários da Sogdiana na época da conquista de Alexandre. A cerâmica indica a coexistência das duas categorias: greco-bactriana e nômade. Existe uma hipótese de infiltração pacifica na região ao longo do periodo $\mathrm{GB}$, análoga àquela imaginada, também com base na cerâmica, em épocas mais recuadas (ver Rapin 1992: 283-287; Bopearachchi 1990: 101-103). Assim, as novas áreas agrícolas que emergiram em época kushan na região bactro-oriental - em direção ao oeste, Imam Sahib (7), e ao sul, Ishkamesh (19), teriam sido colonizadas por populações mistas bactro-kushans (ver Mukhamedjanov 1994: 265-66).

Os traços de ocupação KH1 na sub-região de Dasht-i Qala são numerosos, assim como na maioria das grandes planícies prospectadas ao seu redor. A regressão das superfícies irrigadas nos terraços não significou uma diminuição geral da irrigação após a ocupação kushan, pois um fenômeno oposto foi constatado em outras sub-regiões, que parecem ter sido reabilitadas em época $\mathrm{KH}$, após um aparente eclipse no periodo GB (Gardin 1998: 116). Os indícios de um movimento populacional KH em direção ao oeste, frente às ameaças partas, foram observados (Enoki et al 1994: 180-3) e comprovados arqueologicamente pela pesquisa de Gardin (1998: 116).

Em relação ao periodo kushan, as escavações do sítio de Ai-Khanum teriam revelado traços de uma exploração sistemática de alguns monumentos, reocupados por um periodo que teria se estendido por algumas décadas, mas cujo objetivo foi atribuido à "pilhagem ou à reutilização dos materiais" e, "nunca, à restaura- ção de uma ordem urbana" (Bernard 1994: 104). Por outro lado, ficou evidenciado que os nômades não destruiram os sistemas de irrigação, nem as demais cidades e vilarejos das fases anteriores, o que indica uma opção pela exploração das estruturas preexistentes e não uma devastação das mesmas (ver Enoki et al. 1994: 184-85; Leriche 2007: 138). A maioria das cidades fortificadas preexistentes permaneceu ocupada e as evidências encontradas não revelam nenhuma grande descontinuidade entre os periodos GB e KH. Algo que aparece acompanhado de um crescimento extensivo do sistema de trocas, também documentado arqueologicamente (Litvinsky 1994: 312). Nesse periodo, o planejamento urbano centroasiático, helenístico e indiano se mesclaram e desenvolveram de uma forma e com uma intensidade sem precedentes (ver Le Berre e Schlumberger 1964: 70-4; Fédorov-Davydov 1985: 180-89; Litvinsky 1994: 291-6; Pugachenkova et al. 1994: 331-38; Negmatov 1994: 446-56). Isso se refletiu no crescimento quantitativo da grade de assentamentos urbanos, com a emergência de novas cidades; na ampliação da área urbana das cidades antigas e no aumento da densidade de construções nas malhas urbanas (Litvinsky 1994: 300-1; Leriche 2007: 136-38). Ainda assim, a grande cidade fortificada de Qala-i Zal, cujo apogeu ocorreu em época KH2, foi inevitavelmente descrita de forma comparativa e subordinada por "ecoar o esplendor de $\mathrm{A} i$ Khanum" (Gardin 1998: 116).

\section{Interações regionais: a sincronia e a diacronia na ocupação da Báctria}

Como observaram os próprios pesquisadores franceses, não havia sido realizada qualquer análise quantitativa dos dados obtidos durante o levantamento da região bactro-oriental (Gardin e Lyonnet 1978/79; Gardin 1998). O material de superfície - a cerâmica -, pesquisado por Lyonnet (1997), não foi quantificado de forma a fornecer mais evidências sobre cada ocupação. Mesmo a publicação definitiva das prospecções, como vimos, demorou vinte anos para ser finalizada e não apresentou qualquer 
quantificação em relação à distribuição dos assentamentos no território. Gardin (1998: 127) avaliou os limites dos exercícios interpretativos fundamentados exclusivamente em conjuntos de superfície e considerou o tipo de prospecção realizado um tanto restrito, uma vez que, segundo ele mesmo, nenhum procedimento estatístico ditou a escolha dos sitios prospectados, nem dos fragmentos cerâmicos coletados. Por essa razão, esse arqueólogo acreditava que a análise espacial dos sítios seria um "mero exercicio formal, uma promessa no melhor dos casos de algum sucesso acadêmico, mas infelizmente desprovida de fundamento" (Gardin 1998: 14; grifo nosso). As razões desse descrédito e de um aparente autodemérito em relação à coleta dos dados aparecem expostas de modo claro e objetivo, assim como, justificadas de modo cartesiano e recorrente ao longo de sua análise, entretanto, não nos pareceram suficientes para descartar, de modo tão veemente, uma análise espacial da porção oriental da Báctria.

As dúvidas permaneceram: será mesmo que qualquer análise espacial dessa região estaria realmente desprovida de fundamento, como afirmou Gardin? Seria mesmo um mero exercício formal? Para avaliar essa afirmação do pesquisador, nos debruçamos sobre a seguinte questão: quais as possibilidades e possiveis caminhos que uma investigação pautada pela Arqueologia do Ambiente Construido (ver Aldrovandi 2009b) seria capaz de fornecer para a análise e interpretação da ocupação da região em questão. Nesse sentido, a realização de uma análise espacial da ocupação da região bactrooriental, realizada a partir de um modelo analítico-quantitativo baseado nos dados fornecidos por Gardin (1998) e apresentada a seguir, tem justamente por objetivo aprofundar a compreensão acerca dos resultados apresentados pelos pesquisadores que ali trabalharam.

\section{A quantificação dos assentamentos}

Com base nas informações sobre a prospecção arqueológica da região da
Báctria Oriental e nos mapas das sub-regiões (Gardin 1998) procedemos a uma quantificação do assentamentos em cada uma das 19 subregiões levantadas. Uma tabela com a totalização dos sítios foi elaborada a partir da contagem dos assentamentos presentes no catálogo (Gardin 1998: 35-101) e nos mapas fornecidos (Gardin 1998: 228-345), em cada periodo de ocupação (IB, AQ, GB, $\mathrm{KH})$ e em cada uma das 19 sub-regiões analisadas. Como mencionado anteriormente, foram selecionados os períodos que estão mais diretamente envolvidos com a época de ocupação greco-bactriana, isto é, os dois periodos anteriores (IB e AQ), que formaram as bases para o desenvolvimento da paisagem helenística; e o periodo subsequente $(\mathrm{KH})$, cuja análise possibilita verificar o comportamento dessa paisagem após o fim do domínio helênico na região. Essa tabela, ${ }^{7}$ apresentada de modo sintético abaixo (Fig. 8 ), serviu de base para a análise quantitativa subsequente. Embora, Gardin (1998: 21-8) tenha realizado uma subdivisão cronológica dos periodos IB, AQ e $\mathrm{KH}$, o próprio pesquisador reconheceu que, em muitos casos, as fases não eram suficientemente nitidas (ex. Se IB1 ou IB2 etc.), por essa razão, a quantificação manteve a divisão original de cada periodo.

Os mapas fornecidos por Gardin (1998) são mais detalhados que aqueles fornecidos em sua primeira publicação (Gardin 1978/ 79). Todos foram digitalizados para possibilitar a quantificação e as análises posteriores, somando mais de 80 mapas. Ainda assim, é preciso observar que apenas no caso da subregião de Dasht-i Qala (3) existem mapas distintos para cada periodo de ocupação, o que deixa visivel o número de assentamentos e as modificações diacrônicas ao longo de cada uma das fases. As demais sub-regiões apresentam desdobramentos sobrepostos em

(7) As tabelas originais possuem a numeração de cada sitio, em cada periodo, entretanto por questões de espaço, aqui, são apresentadas apenas as totalizações de cada periodo. 


\begin{tabular}{|c|c|c|c|c|c|}
\hline \multirow{2}{*}{$\begin{array}{l}\text { NÚMERO E NOME } \\
\text { DAS SUB-REGIÕES } \\
\text { (Total diacrônico) }^{8}\end{array}$} & \multicolumn{5}{|c|}{ OCUPAÇÃO POR PERÍODO (Total sincrônico) ${ }^{9}$} \\
\hline & IB1 - IB2 & $\mathrm{AQ1}$ - $\mathrm{AQ2}$ & GB & $\mathrm{GB} / \mathrm{KH}$ & $\mathrm{KH} 1-\mathrm{KH} 2$ \\
\hline 1 Samti $=3(6)$ & & 1 & & & 2 \\
\hline 2 Yangi Qala = $14(16)$ & & 14 & 3 & & 1 \\
\hline 3 Dasht-i Qala $=264$ & 16 & 62 & 202 & & 162 \\
\hline 4 Khwaja Ghar = $12(13)$ & 1 & 3 & 7 & & 5 \\
\hline 5 Hazar Bagh = $11(18)$ & 1 & 7 & 3 & & 2 \\
\hline 6 Archi $=57(71)$ & 4 & 16 & 43 & & 30 \\
\hline 7 Imam Sahib $25(46)$ & & 10 & 5 & & 23 \\
\hline 8 Taluqan $51(62)$ & $(\mathrm{C}=5) 5$ & 28 & 13 & & 22 \\
\hline 9 Chashma Sher 10 (13) & & 4 & 6 & & 2 \\
\hline 10 Khanabad - Kunduz 55 (64) & & 20 & 11 & & 41 \\
\hline 11 Khanabad - Kunduz $19(13)^{10}$ & 7 & 17 & 16 & & 2 \\
\hline 12 Baixo-Kunduz 2 (3) & & & & & 2 \\
\hline 13 Baixo-Kunduz 3 (3) & & & 3 & (2?) & 2 \\
\hline 14 Chaïab 1 (5) & & & 1 & & 1 \\
\hline 15 Rustaq 14 (27) & 2 & 5 & 5 & & 8 \\
\hline 16 Kalafgan $13(25)$ & 3 & 9 & 9 & & 10 \\
\hline 17 Farkhar $11(21)$ & 6 & 6 & 6 & & 9 \\
\hline 18 Bangui 11 (17) & 11 & 11 & 11 & & 9 \\
\hline 19 Ishkamesh 20 (36) & & & 7 & & 18 \\
\hline
\end{tabular}

Total :

Levantamento intensivo em Dasht-i Qala: 264 (350)

Levantamento extensivo nas demais sub-regiões: $332(459)^{11}$

Fig. 8. Tabela com as quantificações totais das ocupações das sub-regiões em cada período e a totalização geral.

um mesmo ou em alguns mapas. ${ }^{12}$ Não fica clara, por exemplo, a razão de Gardin ter subdividido as duas sub-regiões de KhanabadKunduz (10 e 11) e do Baixo Kunduz (12 e 13), se nos próprios mapas fornecidos elas são apresentadas de modo conjunto. Além disso, a

(8) O número de sítios que aparece totalizado nas tabelas refere-se à soma total dos sitios nos periodos aqui estudados (total diacrônico); e a numeração entre parênteses (000), ao total geral, que inclui os periodos posteriores (HF, IS) que não fazem parte desta quantificação, dai a diferença numérica.

(9) Os totais indicam a somatória sincrônica de cada periodo na respectiva sub-região.

(10) Essa discrepância se deve à diferenciação adotada por Gardin (1998: 83) na totalização dos sitios da margem direita do Khanabad e da distribuição fornecida nos mapas (não sistemática) que é apresentada de modo distinto.

(11) Embora Gardin (1998: 14) tenha fornecido o total de 474 sítios, nossa quantificação a partir do inventário e dos ausência de uma apresentação sistemática dos mapas e a divisão aparentemente aleatória dos periodos apresentados nos mesmos (nos casos em que há sítios de mais de um periodo num mesmo mapa), certamente prejudicam a visualização e a análise espacial de cada sub-

mapas somou 459 assentamentos. Há, aparentemente, 15 sítios não listados pelo pesquisador.

(12) Em alguns casos, todos os periodos estão representados num único mapa, como por exemplo as sub-regiões 1 , 4, 5, 9, 12 e 13 (estas duas no mesmo mapa), 14, 17, 18 e 19. Outras sub-regiões apresentam mais de um mapa de periodos de ocupação, com os sítios de periodos subsequentes apresentados num mesmo mapa: sub-região 2 (2 mapas: AQ/GB; KH/HF/ IS); 6 (3 mapas: IB/AQ; $\mathrm{GB} / \mathrm{KH}$; HF/IS); 7 (3: AQ/GB; KH/HF; HF/IS); 8 (3: C/IB/AQ; GB/KH; HF/IS); 10 e 11 (4, apresentadas juntas: AQ/GB; IB/AQ/GB; KH/HF/ IS; KH/HF/IS); 15 (2: IB/AQ/GB; KH/HF/IS); 16 (2: IB/AQ/GB; KH/ HF/IS). 
região. Assim, a análise dessas interações espaciais presentes na paisagem bactro-oriental ao longo de sua ocupação - que, se pensadas sob a ótica de uma morfogênese visual, consistem em conjuntos de assentamentos a formar imagens sobrepostas e em constante mutação, semelhantes àquelas observadas em um caleidoscópio -, não estava diretamente disponivel a partir dos mapas apresentados. Por isso, a realização da tabela com as totalizações dos sitios, apresentada acima, foi de fundamental importância para a análise quantitativa apresentada a seguir.

Cabe também observar que, em um momento posterior, o desdobramento diacrônico desses mapas permitirá uma visualização efetiva da ocupação de cada sub-região por periodo. A partir disso, uma próxima etapa desta pesquisa tem por intenção realizar uma análise dessa ocupação espacial a partir dos fundamentos teóricos fornecidos pela Arqueologia Fractal. Os mapas desdobrados por periodo específico possibilitarão a tomada das coordenadas espaciais de cada sítio, em cada uma das 19 sub-regiões, nos quatro periodos analisados, por meio do uso de imagens de satélite (NASA: Landsat 7 e SRTM) e o uso de programas para Sensoreamento Remoto (ARCGIS e Global Maper) que permitem combinar esses dados sobre a distribuição dos sítios arqueológicos e outros conjuntos de informações geográficas disponiveis, como vem sendo feito em outros estudos recentes sobre a região bactro-gandhariana (ver Petrie 2007; Stride 2007). Isso permitirá reconstruir a ocupação das sub-regiões em um contexto geográfico mais preciso; localizar os sitios identificados nos mapas e inseri-los nas respectivas regiões para tomar as suas coordenadas geográficas. Em seguida, foram firmados contatos para o desenvolvimento de um algoritmo (Labeca-INPE) ${ }^{13}$ capaz de evidenciar

(13) O Dr. Carlos Alexandre Wuensche, pesquisador do Instituto Nacional de Pesquisas Espaciais, INPE - Divisão de Astrofisica, especialista no desenvolvimento de algoritmos para análise de padrões fractais (da Radiação Cósmica de Fundo, resquicio do Big Bang) se mostrou interessado em colaborar com esse projeto em Arqueologia Fractal na região Bactro-oriental, algo ainda inédito no Brasil. se as ocupações em cada uma das sub-regiões e em cada periodo apresentam um padrão passivel de ser descrito a partir da geometria fractal. ${ }^{14} \mathrm{Os}$ resultados obtidos, por sua vez, possibilitarão realizar uma análise mais abrangente e propor uma interpretação mais precisa sobre a ocupação espacial da região bactro-oriental.

\section{A quantificação específica das sub-regiões}

A partir dos dados obtidos na somatória apresentada na Figura 8, os sitios foram quantificados de modo sistemático dentro de uma perspectiva sincrônica em cada uma das 19 sub-regiões e, também, foram levantados aqueles assentamentos que apresentaram diacronia, i.e., ocupação ao longo de mais de um dos periodos pesquisados.

Dada a impossibilidade, devido ao limite de espaço, de apresentar os resultados especificos da análise quantitativa e os gráficos correspondentes a cada uma das 19 sub-regiões quantificadas, ${ }^{15}$ apresentamos a seguir apenas

(14) O termo fractal foi cunhado por Benoit B. Mandelbrot [Les objets fractals: forme, hasard et dimension. Paris: Flammarion, 1977] para designar algo autossimilar, uma abstração matemática que permite quantificar qualidades que, de outra maneira, não poderiam ser quantificadas, como o grau de regularidade ou irregularidade de um objeto, ou em nosso caso, de uma cidade ou região. (15) Os 57 gráficos preparados ao longo da pesquisa encontram-se a disposição para consulta com a autora. Os três gráficos especificos realizados para cada uma das 19 sub-regiões são constituidos por: (a) um histograma da quantidade total de assentamentos em cada periodo numa dada região (IB, AQ, GB, KH); (b) um histograma do percentual total de assentamentos em cada periodo (IB, AQ, GB, KH); (c) um histograma da quantidade de assentamentos com ocupação em cada periodo: é representado o total de assentamentos existentes em um periodo especifico (IB, $\mathrm{AQ}, \mathrm{GB}, \mathrm{KH})$, ou dois periodos (ex. AQ/KH, GB/KH etc.), três (ex. IB/AQ/KH/, AQ/ $\mathrm{GB} / \mathrm{KH}$ etc.), ou até quatro periodos no mesmo local (ex. $\mathrm{IB} / \mathrm{AQ} / \mathrm{GB} / \mathrm{KH}$ etc.) e segundo a legenda fornecida ao lado do gráfico. Neste último tipo de histograma, a quantidade de assentamentos é indicada no lado direito de cada barra horizontal. Cabe notar que se trata, portanto, de um gráfico do número de ocupações presentes em um ou mais periodos que, por sua vez, podem ou não ter sido sequenciais (diacronia direta ou sequencial). Isto é, enquanto alguns dos assentamentos foram ocupados consecutiva e recorrentemente em duas 
uma delas - Dasht-i Kala (3) -, que corresponde à região mais densamente ocupada desde os primórdios e que teria recebido o influxo helenístico em maior escala. As demais serão discutidas em seguida, junto dos gráficos gerais. ${ }^{16}$

\subsection{A sub-região de Dasht-i Qala (3)}

Na região da planície da planície de Dasht-i Qala, localizada a oeste da região do Rustaq e ao leste da confluência entre o rio Oxus e o Kokcha, encontravam-se os importantes sitios de Shortugaï (IB), Kohna Qala (AQ) e Ai-

ou mais épocas, outros apresentaram ocupações intercaladas, isto é, foram ocupados em um determinado periodo, abandonados e novamente reocupados e um ou mais periodos posteriores. Esse tipo de análise, apresentada em um gráfico, mostra-se extremamente importante, pois permite acessar todas as variações em relação às ocupações diacrônicas, o que não é possivel verificar nas quantificações totais apresentadas nos gráficos de tipo (a) e (b), que são sincrônicas. Ao produzir estes gráficos (de cada subregião), optamos por manter representados os periodos isolados (IB, AQ, GB, KH) e apresentar apenas as sequências diacrônicas existentes em cada sub-região, ao invés de indicar no gráfico todas as variáveis possiveis (mesmo que iguais a 0 ), isto teve por objetivo tornar a visualização da variabilidade diacrônica em cada sub-região mais clara.

(16) Neste último tipo de histograma, a quantidade de assentamentos é indicada no lado direito de cada barra horizontal. Cabe notar que se trata, portanto, de um gráfico do número de ocupações presentes em um ou mais periodos que, por sua vez, podem ou não ter sido sequenciais (diacronia direta ou sequencial). Isto é, enquanto alguns dos assentamentos foram ocupados consecutiva e recorrentemente em duas ou mais épocas, outros apresentaram ocupações intercaladas, ou seja, foram ocupados em um determinado periodo, abandonados e novamente reocupados e um ou mais periodos posteriores. Esse tipo de análise, apresentada em um gráfico, mostra-se extremamente importante, pois permite acessar todas as variações em relação às ocupações diacrônicas, o que não é possivel verificar nas quantificações totais apresentadas nos gráficos de tipo (a) e (b), que são sincrônicas. Ao produzir estes gráficos (de cada sub-região), optamos por manter representados os periodos isolados (IB, AQ, GB, KH) e apresentar apenas as sequências diacrônicas existentes em cada sub-região, ao invés de indicar no gráfico todas as variáveis possiveis (mesmo que iguais a 0 ), isto teve por objetivo tornar a visualização da variabilidade diacrônica em cada sub-região mais clara, indicando somente aquelas que realmente existiram.
Khanum (GB). Essa foi a região escavada pelo DAFA e prospectada de maneira intensiva pela equipe de Gardin (1978/79; 1998). A subregião apresentou um total geral de 350 sítios prospectados, 264 dos quais pertencem aos periodos sobre os quais nossa análise se fundamentou (numeração dos assentamentos: 1 a 295; 400 a 454 - não foram descritos de modo sistemático; os sitios anteriores, 295 ao 399, foram inutilizados por Gardin, em sua publicação final). ${ }^{17}$ Ela é, sem dúvida, a sub-área que apresentou maior densidade de assentamentos em todos os periodos de ocupação, uma quantidade que não encontra paralelos em nenhuma outra área prospectada.

Ali foram encontrados 16 sítios do periodo IB, que marcou o início da ocupação dessa região; esse número subiu para 62 assentamentos durante o periodo AQ; em seguida, para 202 sitios em época GB; e, no periodo $\mathrm{KH}$ subsequente, embora esse número tenha caído para 162 assentamentos, ainda permanece bastante expressivo. Em termos percentuais, os assentamentos da Idade do Bronze somam 3\% do total; os do periodo aquemênida representam $14 \%$ do total de sítios que foram levantados na região; os assentamentos greco-bactrianos perfazem um total de $46 \%$; e os sitios kushan correspondem a 37\% (Fig. 9). No entanto, esses são percentuais totais, cuja interpretação pode distorcer, em certa medida, o que realmente ocorreu na região.

Isto porque, em relação à diacronia sequencial (Fig. 10), sete sítios apresentaram ocupação apenas durante o periodo IB; três deles foram ocupados durante os periodos IB/GB; três sítios nos periodos IB/AQ/GB/KH, ou seja, tiveram ocupação continua em todas as fases; dois sítios foram ocupados durante os periodos IB/ $\mathrm{GB} / \mathrm{KH} ; 16$ assentamentos existiram apenas durante o periodo $A Q ; 15$ sítios apresentaram ocupação nos periodos AQ/GB; 22 sítios, nos periodos $\mathrm{AQ} / \mathrm{GB} / \mathrm{KH}$; cinco sitios foram

(17) Mapas fornecidos: fig. 3.1 (geral); 3.2 e 3.3 (sitios prospectados áreas Sul e Norte); 3.4 (zonas de AiKhanum, urbana, semi-urbana e rural); 3.8 a 3.11 (periodos IB, AQ, GB, KH), em Gardin (1998: 234-43). 


\section{Assentamentos na Planície de Dasht-i Qala}
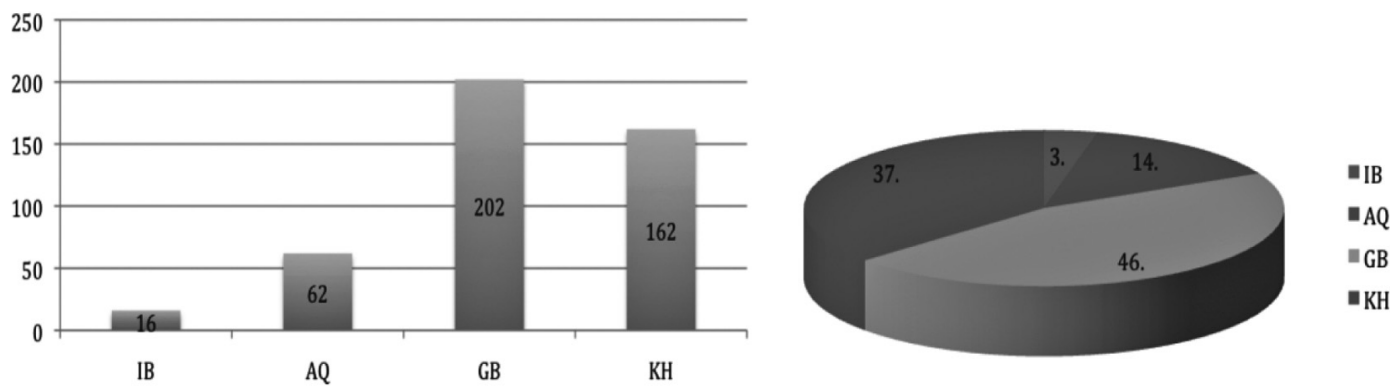

Fig. 9. Histogramas da quantidade de assentamentos em cada periodo de ocupação e gráfico da quantidade percentual de assentamentos em cada periodo.

ocupados nos periodos $\mathrm{AQ} / \mathrm{KH}$; no periodo $\mathrm{GB}$ surgiram 72 sítios cuja ocupação limitou-se apenas a essa fase; 86 sitios foram ocupados nos periodos $\mathrm{GB} / \mathrm{KH} ; 32$ deles surgiram no periodo $\mathrm{KH}$. A partir dessa constatação, começa a se configurar uma paisagem mais fluida e, portanto, mais próxima à realidade que a arqueologia é capaz de recuperar. Nesse sentido, vemos que o início da ocupação dessa sub-região remonta ao periodo da Idade do Bronze, época em que surgem 16 assentamentos, destes, sete foram ocupados somente nessa fase e abandonados em seguida, outros três continuaram ocupados no periodo aquemênida, sendo que três sitios IB também foram reutilizados durante o periodo grecobactriano; e dois permaneceram em uso durante o periodo kushan; sendo que três deles estiveram ocupados continuamente em todas as fases. Outros três sítios IB, que haviam sido abandonados, foram reocupados durante o periodo grecobactriano; desses, dois permanecem ocupados em época kushan.

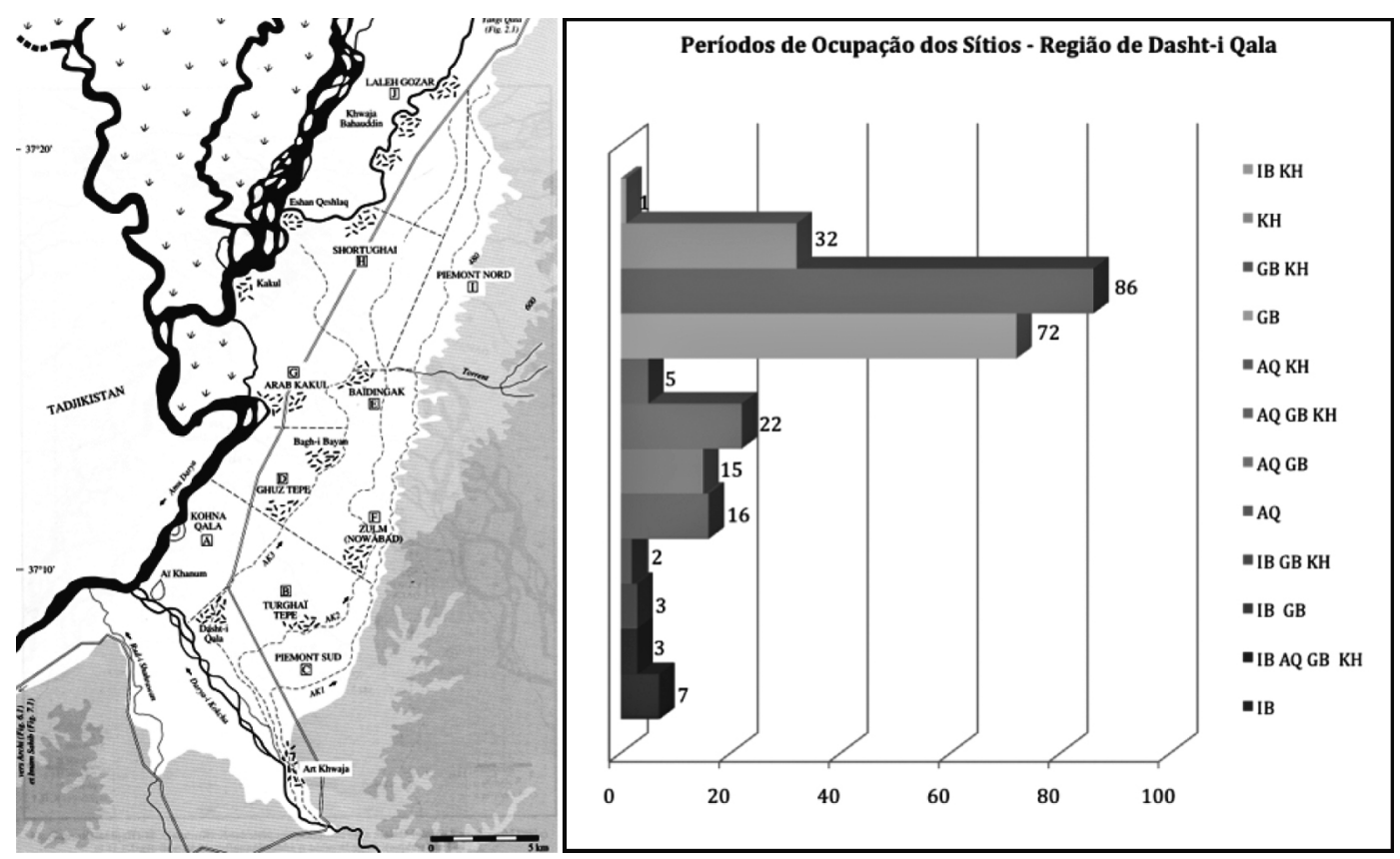

Fig. 10. Mapa da região de Dasht-i Qala dividida em 10 setores (em Gardin 1998: 234); e histograma com a quantidade de assentamentos com ocupação em cada periodo (diacronia sequencial). 
Entre os 62 sitios existentes em época aquemênida nessa região, 53 deles foram novas fundações. Dentre elas, 16 estiveram ocupadas somente durante esse periodo, $15(+22)$ continuaram ocupadas na época greco-bactriana, sendo que, dessas, 22 foram também utilizadas no periodo kushan subsequente, sendo que uma delas era uma fortaleza (46). Entre os sítios aquemênidas abandonados, cinco foram reocupados em periodo kushan.

No periodo greco-bactriano existiram 202 ocupações, das quais 158 são novas fundações. Destas, 72 existiram somente em época GB e 86 tiveram continuidade em época $\mathrm{KH}$. A esses assentamentos somaram-se os 28 preexistentes (IB e $\mathrm{AQ}$ ), que continuaram em uso e possivelmente foram "re-fundados". Em época kushan surgiram 32 novos assentamentos (que se somam aos 86 já existentes) e um sítio do periodo IB foi reocupado.

Essa sub-região apresentou uma extrema complexidade em sua ocupação. Duas fortalezas, uma de periodo aquemênida, Kohna Qala (47; setor A, 25 ha entre os muros externos, 14 ha no interior da cidade, periodo $\mathrm{AQ}$ ) e outra de época greco-bactriana Arab Kakul (160; setor G) permaneceram ocupadas nos periodos subsequentes. Além desses sitios, entre aqueles que Gardin (1998: 139) chamou extraordinários encontra-se a cidade elevada de Ghuz Tepe (57.58; setor D; com mais de 2,5 ha, H 12m; periodo AQ); os sitios 82 (setor G; $120 \mathrm{X}$ $80 \mathrm{~m}, \mathrm{H} 3 \mathrm{~m}$; periodos IB a HF) e 171 (setor G; 90 X 40 m, H 6m; periodos AQ[?] a KH); e o monte de Turghaï Tepe (4; setor B; periodos GB-KH). As únicas fortalezas dessa sub-região listadas por Gardin (1998: 136-137) são: a cidadela circular de Kohna Qala (47); a maior cidade, Ai-Khanum (135 ha; GB); e a cidade retangular de Arab Kakul (160). Shortugaï (setor $\mathrm{H}$ ), curiosamente, não figura na listagem como uma fortaleza, no entanto, se essa cidade seguiu o padrão dos assentamentos do Vale do Indo e por estar próxima a um rio, certamente, deve ter possuido muralhas.

Destaca-se, também, outro ponto interessante: o fato, por exemplo, de que no periodo IB havia 16 sitios e, na época seguinte, esse número se elevou para 62, o que significa um aumento proporcional de um fator 2,88 [i.e.: 62-16=46, 46:16=2,88]. Enquanto, no periodo seguinte GB, que apresenta um total de 202 sitios ocupados, o crescimento proporcional, por sua vez, foi de 2,26, ou seja, proporcionalmente inferior ao periodo anterior. No periodo KH, há uma diminuição de 0,20 no número de ocupações. Em termos percentuais, isto significou um aumento de $288 \%$ dos assentamentos em época $A Q$, frente àqueles existentes na Idade do Bronze; seguido de um aumento percentual de $226 \%$ em época GB; e um decréscimo de $20 \%$ na ocupação dessa sub-região no periodo KH. Assim, é fundamental observar que, embora numericamente a quantidade de sitios do periodo GB seja superior, proporcionalmente, à quantidade total do periodo anterior, a ocupação da sub-região e as novas fundações foram mais intensas em época AQ. Também é necessário ressaltar que, embora tenha havido um decréscimo da ocupação dessa sub-região em época $\mathrm{KH}$, ele não é tão considerável como se esperaria quando se ouve falar do suposto "abandono" da cidade de AiKhanum e dessa sub-região, uma vez que $80 \%$ dela permaneceu ocupada.

Embora Ai-Khanum tenha sido considerada pelos pesquisadores uma fundação greco-bactriana, é importante lembrar que a cidade apresentava edificios de estilo persa, como o próprio templo principal da cidade, o que coloca em dúvida os critérios utilizados pelos arqueólogos em relação à datação relativa à fundação dessa cidade. No entanto, tanto na obra de Lyonnet (1997) quanto na sintese final de Gardin (1998), isso não foi levado efetivamente em consideração. A ocupação dessa porção da sub-região de Dasht-I Qala certamente remonta, no minimo, à época aquemênida, com a fortaleza de Kohna Qala (47), como vimos, a apenas $2 \mathrm{~km}$ da pólis grega. Apesar de mencionar a proximidade da fortaleza aquemênida e a falta de evidências que indiquem seu abandono em época $\mathrm{GB}$, o pesquisador reiterou que o planejamento urbano de $\mathrm{Ai}$ Khanum foi "certamente grego" (Gardin 1998: 46). Voltaremos a essas questões adiante.

\section{A quantificação geral}

\subsection{Os assentamentos de cada sub-região em cada período histórico}

A partir da análise especifica de cada uma das 19 sub-regiões procedemos, em seguida, à 
execução de uma quantificação geral das mesmas por periodo de ocupação (Fig. 11). Esse procedimento permitiu visualizar graficamente o crescimento ou declinio do número de ocupações em cada uma das épocas abrangidas na presente pesquisa.

A sub-região da planície de Dasht-i Qala (3) aparece em destaque, conforme observado acima, como a área com maior ocupação em todos os periodos consecutivos, além disso, também é possível observar que, enquanto o número de sítios cresce intensamente durante as três primeiras fases de ocupação (IB, AQ, GB), houve um decréscimo (20\%) no periodo seguinte (KH). A sub-região de Archi (6) apresenta um tipo de crescimento semelhante, com aumento continuo nas épocas IQ, AQ, GB e um declinio subsequente no periodo KH. As sub-regiões de Khwaja Ghar (4) e Chashma Sher (9) seguem um tipo de sequência semelhante àquelas observadas nas regiões de Dasht-i Qala (3) e Archi (6), com pouca ou nenhuma ocupação na época IB, seguindo um crescimento entre o periodo AQ e GB, e um declínio posterior na época $\mathrm{KH}$.

Por outro lado, o número de assentamentos na sub-região de Khanabad-Kunduz (10), surgidos em época $A Q$, sofreu um declinio no periodo $\mathrm{GB}$ e, no periodo subsequente $\mathrm{KH}$, cresceu exponencialmente, praticamente quadruplicando. A sub-região vizinha, Khanabad-Kunduz (11), apresentou um inicio de ocupação em época mais remota (IB), que duplicou no periodo $A Q$, permaneceu estável em época GB e foi praticamente abandonada no periodo KH. A sub-região do Taluqan (8), aparentemente a primeira a ser ocupada, já possuía um número representativo de ocupações no Calcolitico, que permaneceu estável na Idade do Bronze, cresceu substancialmente na fase AQ subsequente, decresceu de modo considerável em época GB e apresentou uma retomada do crescimento no periodo $\mathrm{KH}$, mas que não chegou a alcançar o mesmo grau de ocupação encontrado em época AQ. As sub-regiões de Rustaq (15) e Iman Sahib (7), Kalafgan (16), embora possuam uma quantidade menor de assentamentos, apresentaram um tipo semelhante de ocupação. Elas cresceram na fase AQ, apresentaram um declínio ou estabilidade em época GB e uma retomada do crescimento no periodo posterior $\mathrm{KH}$.

As sub-regiões de Yangi-Qala (2) e Hazar Bagh (5) apresentaram um grande crescimento em época $A Q$, mas foram praticamente abandonadas em época GB e KH. As sub-regiões de Farkhar (17) e Bangui (18), embora possuam uma quantidade reduzida de assentamentos, apresentaram um tipo semelhante de ocupação. Elas permanecem estáveis nos periodos IB, AQ e GB, somente em época KH é que se comportaram de maneira distinta: a primeira cresceu enquanto a segunda decresceu. Há ainda subregiões com número de ocupações extremamente baixos como Samti (1), o Baixo Kunduz (10 e 11) e Chaiab (14), com apenas um ou dois sitios em cada periodo, nenhuma delas ocupada no periodo IB e todas com dois sítios em época Kushan.

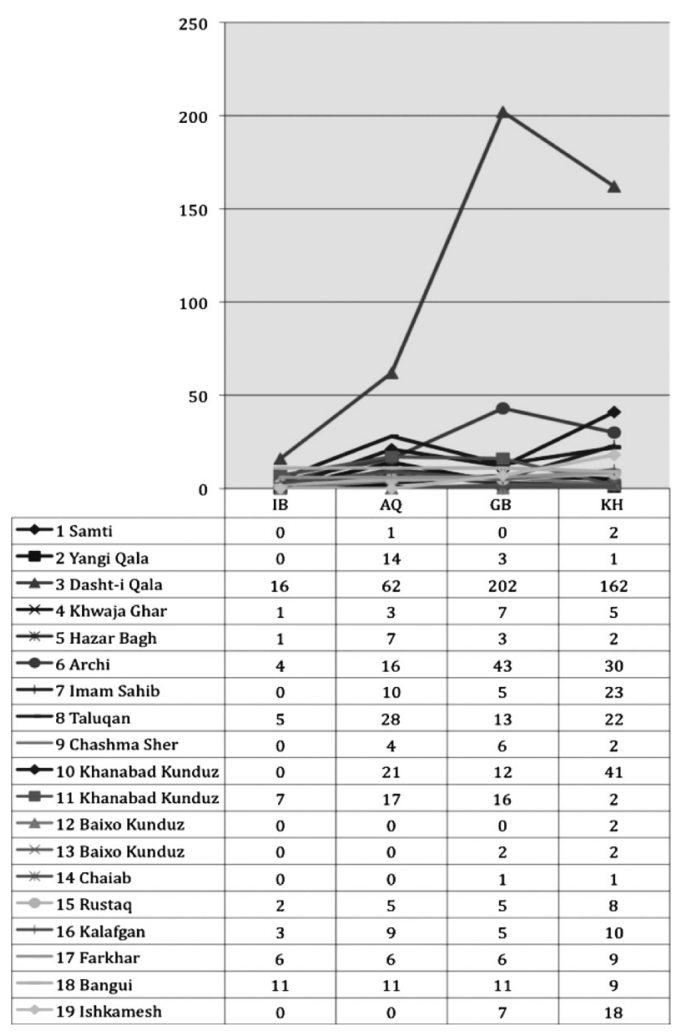

Fig. 11. Gráfico com a quantidade de sitios por subregião em cada período. 


\subsection{Os assentamentos de cada período históri- co em cada sub-região}

A partir da análise especifica da ocupação em cada uma das 19 sub-regiões também foi elaborado um quadro geral da quantidade de sitios existentes em cada uma delas em cada periodo (Fig. 12). Assim, na Idade do Bronze, as áreas ocupadas por maior quantidade de sitios foram, respectivamente, a planície de Dasht-i Qala (3), seguida pelas sub-regiões de Bangui (18); KhanabadKunduz (11); Farkhar (17); Taluqan (8); Archi (6); Kalafgan (16); Rustaq (15); Khwaja Ghar (4); e Hazar Bagh (5). No periodo Aquemênida, as sub-regiões mais densamente ocupadas foram respectivamente: Dasht-i Qala (3); Taluqan (8); KhanabadKunduz (10); Khanabad-Kunduz (11); Archi (6); Yangi Qala (2); Bangui (18); Imam Sahib (10); Kalafgan (16); Hazar Bagh (5); Farkhar (17); Rustaq (15); Chashma Sher (9); Khwaja Ghar (4); Samti (1). No período Greco-Bactriano, tivemos as sub-regiões de $\mathrm{Ai}$ Khanum (Dasht-i Qala 3); Archi (6); Kanabad-Kunduz (11); Taluqan (8); KhanabadKunduz (10); Bangui (18); Khwaja Ghar (4); Chashma Sher (9); Farkhar (17); Imam Sahib (7); Rustaq (15) e Kalafgan (16); Yangi Qala (2); Hazar Bagh (5); Baixo Kunduz (13); Chaiab (14). A época Kushan apresentou uma densidade de ocupação na seguinte ordem: Dasht-i Qala (3); Kanabad-Kunduz (10); Archi (6); Imam Sahib (7); Taluqan (8); Ishkamesh (19); Kalafgan (16); Farkhar

(17); Bangui (18); Rustaq

(15); Khwaja Ghar (4); Samti

(1); Hazar Bagh (5);

Chashma Sher (9);

Khanabad-Kunduz (11);

Baixo Kunduz (12 e 13); Yangi Qala (2); Chaiab (14).

\section{As áreas de ocupação: a sequência diacrônica}

Após a quantificação especifica e geral das 19 sub-regiões, verificamos também a proporção de assentamentos que cada uma dessas áreas apresentou em cada periodo de ocupação, i.e., as proporções sincrônicas da ocupação da região. Os mapas fornecidos por Gardin (1998: 220-223; ver Fig. 7 neste), embora úteis para a visualização geral do aumento/decréscimo das áreas ocupadas em cada periodo, não permitiam inferir as dimensões reais das ocupações das sub-regiões em cada um deles, uma vez que a mancha (tracejado) dá a impressão de que se tratava de uma ocupação homogênea quando, na verdade, se tratava de ocupações extremamente heterogêneas em cada sub-região - mais ou menos densas, conforme podemos observar abaixo (Fig. 13).

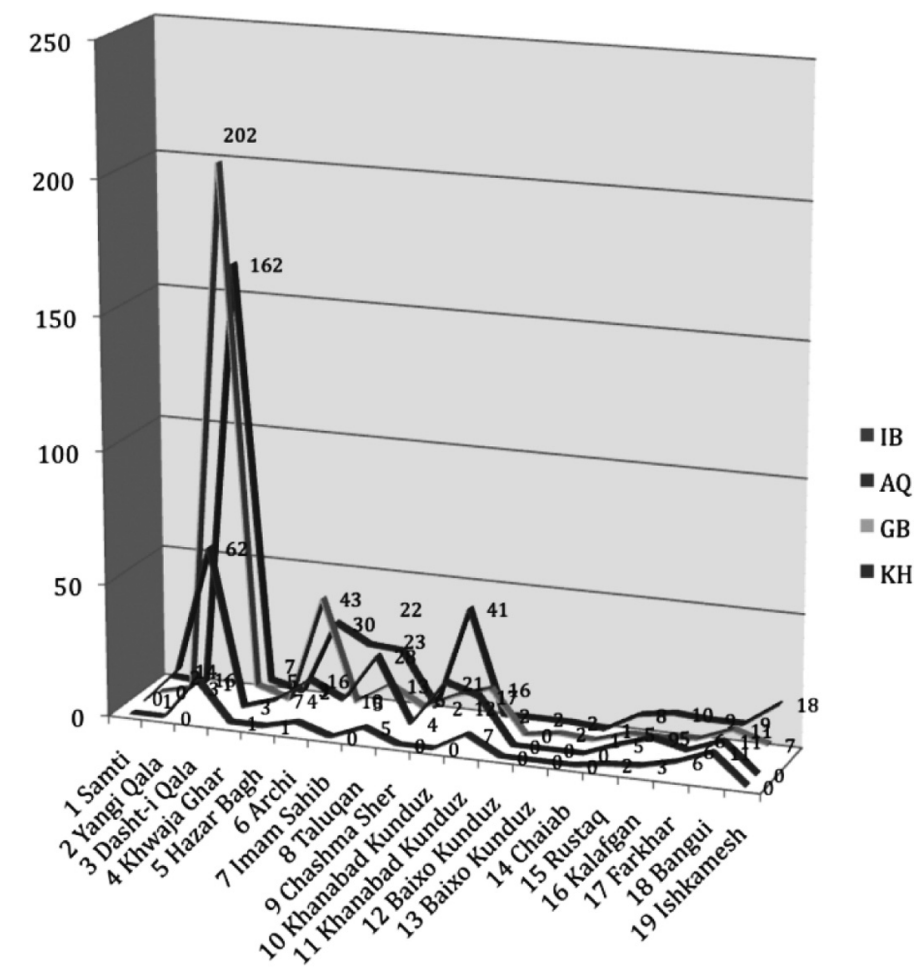

Fig.12. Histograma com a quantidade de sítios de cada periodo em cada sub-região. 


\subsection{Período IB}

Na Idade do Bronze, a ocupação da área da planície de Dasht-i Qala (3) representa 29\% dos sitios existentes na Báctria oriental. Em seguida, temos a área de Bangui (18) com 20\% das ocupações; Kanabad-Kunduz (11) com 13\%; Farkhar (17) com 11\%; Taluqan (8) com 9\%; Archi (6) com 7\%; Kalafgan (16) com 5\%; Rustaq (15) com 4\%; Khwaja Ghar (4) e Hazar Bagh (5), cada uma com 2\%. Nesse periodo, as demais sub-regiões ainda não se encontravam ocupadas e, portanto, não aparecem representadas. Assim, é possivel observar que embora a ocupação da sub-região do Taluqan (8) remonte ao Calcolítico e tenha sido, possivelmente, a primeira área ocupada na região bactro-oriental, a partir da Idade do Bronze houve uma grande ampliação das áreas ocupadas e a planície de Dashti Qala passou a figurar como a mais densa, apresentando quase um terço do total de assentamentos do período. As planícies de Dasht-i Qala e Bangui representam, praticamente, a metade das áreas ocupadas no período. Apesar de KanabadKunduz ter apresentado 7 sítios do período IB, i.e, 13\% da ocupação geral da região, essa ocupação não aparece marcada no mapa de Gardin (1998: 220); enquanto a vasta área de de Archi, por exemplo, aparece claramente marcada, embora sua ocupação represente apenas 7\% do total.

\subsection{Período $A Q$}

No periodo AQ, a ocupação da área da planície de Dasht-i Qala (3) também representa 29\% dos sítios existentes na Báctria oriental. Em seguida, temos a área do Taluqan (8) com 13\%; Khanabad-Kunduz (10) com 10\%; KhanabadKunduz (11) com 8\%; Yangi Qala (2) com 7\%; Archi (6) com 7\%; Bangui (18) com 5\%; Imam Sahib (7), com 5\%; Kalafgan (16) com 4\%; Hazar Bagh (5) com 3\%; Farkhar (17) com 3\%; Rustaq (15) com 2\%; Chashma Sher (9) com 2\%; Khwaja Ghar (4) com 1\%. É interessante notar, nesse caso, que embora o número de sitios em Dasht-i Qala, como vimos, tenha crescido exponencialmente nesse periodo, se observarmos a região como um todo e a compararmos ao período IB, esse número continua a representar 29\% do total, o que indica um desenvolvimento intenso e igualmente considerável das outras sub-regiões nessa época.

\begin{tabular}{|c|c|c|c|}
\hline Idade do Bronze & 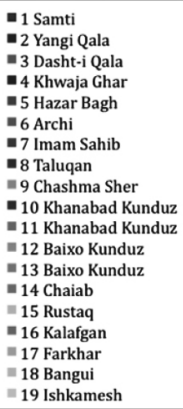 & Período AQ & 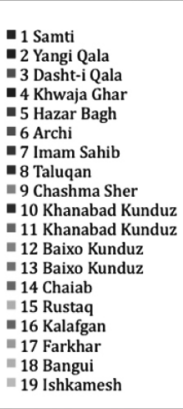 \\
\hline 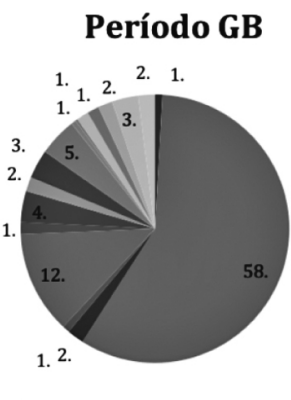 & 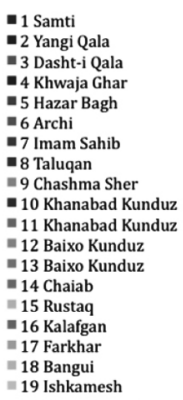 & $\begin{array}{l}\text { Período KH } \\
\text { 3. } 1 .\end{array}$ & $\begin{array}{l}\text {-1 Samti } \\
\text { - } 2 \text { Yangi Qala } \\
\text { =3 Dasht-i Qala } \\
\text { = } 4 \text { Khwaja Ghar } \\
=5 \text { Hazar Bagh } \\
=6 \text { Archi } \\
\text { = } 7 \text { Imam Sahib } \\
=8 \text { Taluqan } \\
=9 \text { Chashma Sher } \\
=10 \text { Khanabad Kunduz } \\
=11 \text { Khanabad Kunduz } \\
=12 \text { Baixo Kunduz } \\
=13 \text { Baixo Kunduz } \\
=14 \text { Chaiab } \\
=15 \text { Rustaq } \\
=16 \text { Kalafgan } \\
=17 \text { Farkhar } \\
=18 \text { Bangui } \\
=19 \text { lshkamesh }\end{array}$ \\
\hline
\end{tabular}

Fig. 13. Quantidade percentual de assentamentos durante os 4 periodos nas 19 sub-regiões. 


\subsection{Período $G B$}

No periodo GB, a ocupação da área da planície de Dasht-i Qala (3) representa 58\% dos sitios existentes na Báctria oriental, isto é, antes essa sub-região possuia $29 \%$ das ocupações e agora representa o dobro. A seguir, temos a área vizinha de Archi (6) com 12\%; Khanabad-Kunduz (11), com 5\%; Taluqan (8) com 4\%; Khanabad-Kunduz (10), com 3\%; Bangui (18), com 3\%; Khwaja Ghar (4) com 2\%; Chashma Sher (9) com 2\%; Farkhar (17) com 2\%; Ishkamesh (19) com 2\%; em seguida, com apenas $1 \%$ da área ocupada temos Yangi Qala (2), Hazar Bagh (5), Imam Sahib (7), Baixo Kunduz (13), Rustaq (15) e Kalafgan (16). Além de ser a região mais densamente ocupada, a concentração de sítios em Dasht-i Qala, com mais da metade das ocupações desse periodo, acompanhada de uma diminuição da ocupação de algumas sub-regiões, representa o movimento centrípeto observado anteriormente por Gardin (1978/79: 138-39).

\subsection{Período $\mathrm{KH}$}

No periodo KH ocorreu uma mudança mais visivel na configuração da ocupação bactro-oriental. A ocupação da área da planície de Dasht-i Qala (3) representou 46\% dos sítios existentes, ou seja, ela continuou a ser a subregião com maior densidade de assentamentos. No entanto, o equilibrio na ocupação das demais áreas apresentou uma certa modificação. Assim, temos a área de Kanabad-Kunduz (10) com 12\%; Archi (6) com 9\%; Imam Sahib (7) com 7\%; Taluqan (8) com 6\%; Ishkamesh (19) com 5\%; Kalafgan (16) com 3\%; Bangui (18), com 3\%; Farkhar (17) com 3\%; Rustaq (15) com 2\%; em seguida, com apenas $1 \%$ da área ocupada temos Samti (1); Khwaja Ghar (4); Hazar Bagh (5); Chashma Sher (9); KhanabadKunduz (11); Baixo Kunduz (12); Baixo Kunduz (13) (Gráfico 63). Na época Kushan, observouse uma distribuição um pouco mais equilibrada nos percentuais de ocupação das sub-regiões, algumas recuperam a importância que tiveram no periodo AQ, como Khanabad-Kunduz (10) e Taluqan (8). Paralelamente, áreas antes pouco ocupadas desenvolveram-se consideravelmente, como ocorreu na sub-região de Imam Sahib (7) e Ishkamesh (19). Outras, ainda, como Hazar Bagh (5), aparecem menos povoadas no mapa de Gardin (1998: 223) em época KH e na quantificação continuaram a apresentar apenas $1 \%$ das ocupações totais. No caso de Hazar Bagh, parece ter ocorrido um decréscimo maior entre a época $\mathrm{AQ/GB}(3 \%)$ e não $\mathrm{GB} / \mathrm{KH}$ (1\%). Essas mudanças na dispersão das ocupações, principalmente nos casos em que há um movimento ascendente em época kushan, podem ter encontrado suas causas justamente em uma ausência ou baixa presença grecobactriana nas sub-regiões, o que teria viabilizado ou facilitado a penetração nômade.

\section{Considerações sobre a morfogênese espacial bactro-oriental}

Os métodos quantitativos se tornaram extremamente importantes para a Arqueologia durante as últimas décadas do século XX mas, ao longo desse tempo, os arqueólogos também se conscientizaram dos problemas envolvidos nas análises quantitativas, pois as técnicas utilizadas na quantificação irão, inevitavelmente, ter um efeito direto sobre os resultados alcançados e, por sua vez, sobre as conclusões obtidas a partir dos mesmos (ver Shennan 1988; Drennan 1996). Assim, a escolha do tipo de método estatístico a ser aplicado é extremamente importante para o pesquisador. Entretanto, é necessário também considerar que a metodologia utilizada nas pesquisas quantitativas, embora possua restrições como qualquer outro tipo de análise, possibilitou à presente pesquisa compor um quadro, sob certos aspectos, mais preciso sobre a ocupação da região bactro-oriental, sem depender das reconstruções históricas apresentadas por estudiosos que, em uma parte considerável dos casos, se basearam em informações indiretas fornecidas por fragmentos de narrativas dos historiadores clássicos (ver Aldrovandi 2009a) ou em cronologias dinásticas fornecidas a partir de análises numismáticas, muitas vezes problemáticas (ver Guillaume 1990). Como essa 
quantificação se baseou nos dados fornecidos por Gardin (1998), ela certamente esteve circunscrita à região prospectada, mas pode servir de exemplo para estudos futuros desse tipo em outras áreas da antiga Báctria, ou mesmo de outras regiões.

Além disso, a grande complexidade que existiu nessa área permaneceu, durante muito tempo, ofuscada pela ótica de perspectivas reducionistas, paradigmáticas e etnocêntricas. A análise apresentada por Alcock (1994), por exemplo, fundamentada pelos levantamentos de superfície realizados no mundo Helenístico, foi uma das primeiras a questionar essa postura, ao fornecer uma nova perspectiva sobre esse periodo histórico e que, por sua vez, remete àquela desenvolvida em nossa pesquisa. Como lembrou a pesquisadora, as influências interpretativas antigas foram coloridas por crenças e comportamentos contemporâneos imperialistas e também, como vimos, eurocêntricos:

O triunfo da cultura grega tomando e civilizando as populações orientais indiferenciadas, conquistadas sem esforço por Alexandre, continuou a dominar numerosas discussões sobre a "colheita do Helenismo". Consequentemente, uma despreocupação acadêmica desconsiderou as inúmeras sociedades nativas e tradições que se fundiram aos reinos greco-macedônicos. Até mesmo grandes impérios, como os aquemênidas, que tinham anteriormente dominado o mundo Helenístico por um longo tempo, foram pouco considerados. Sendo vistos por muitos como uma tabula rasa, que aguardava a impressão da civilização. Um resultado dessa visão helenocêntrica foi a percepção do mundo Helenístico como um fenômeno relativamente unitário (Alcock 1994: 171).

Essa visão de homogeneidade do mundo helenístico aparece claramente expressa na obra de Tarn (1951; Tarn e Griffith, 1952: 3) que enfatizou o uso de uma lingua comum, da cultura grega e de trocas comerciais sem precedentes, ou seja, de uma unidade do ponto de vista de civilização e de modo de vida que teria sido alcançada apenas pelos e a partir dos gregos. Esse tipo de abordagem decorre da ênfase acadêmica atribuída a um poder dominante e persuasivo e ao uso que essa fez da influência grega em terras estrangeiras, em termos quase sempre unilaterais. Como vimos, esse tipo de postura permeia, mesmo que de modo por vezes subliminar, boa parte das pesquisas realizadas pelo DAFA e, em menor proporção, aquelas apresentadas pelos demais pesquisadores que trabalharam na região.

Esse tipo de abordagem também se deveu à natureza das fontes mais frequentemente consultadas: a documentação textual. O estudo de tradições documentais alternativas, as fontes orientais, foi deixado de lado ou, mais comumente, sua análise não foi integrada às histórias dominantes, aquelas escritas pela perspectiva do conquistador (cf. Alcock 1994: 173). Ou seja, uma parte considerável da história helenística é fundamentalmente história colonialista, como já havia discutido Trigger (1989). Isso diz respeito, de certa maneira, a uma questão mais ampla: sobre a natureza e das pré-concepções e estereótipos do discurso ocidental e etnocêntrico sobre o Oriente e seus regimes despóticos, tão bem explicitadas por Said (1978) e, mais tarde, revistos por Bhabha (1994) e outros estudiosos do pós-colonialismo. Uma outra forma, não menos equivocada, de abordagem é aquela que considera o periodo Helenístico instável e mal sucedido (ver Alcock 1994: 173). Sob esse ponto de vista, as estruturas politicas helenísticas teriam sido enfraquecidas, de algum modo, pelo contato com o Oriente e privadas da pureza e integridade da pólis clássica, algo observado anteriormente, por exemplo, no discurso que permeia a pesquisa de Bernard (1967; 1974) sobre Ai-Khanum. O foco dos estudos, até a década de 1970, esteve centrado nas influências unilaterais da cultura grega sobre as tradições autóctones e desconsiderou, na maioria dos casos, a provável existência de interação ou de resistência cultural.

No final do século XX, muitos pesquisadores passaram a enfatizar a importância de se estudar os regimes preexistentes em cada região, antes do advento grego, e a natureza precisa da sua interação com o poder dominante. A 
concepção de uma cisão histórica acompanhada da chegada de algo inteiramente novo nas regiões conquistadas foi criticada principalmente pelos estudiosos do Império Aquemênida, notadamente por Briant (1982; 1984; 1996). Inseridos em uma perspectiva de longa-duração, os argumentos desse pesquisador baseiam-se em uma relativa continuidade entre o poder aquemênida e helenístico, percebendo estruturas organizacionais similares, uma infraestrutura rural basicamente igual e continuidades na administração e politica imperial, antes desconsideradas. Como bem observou Briant (1982: 159-60), "qualquer entendimento válido do oikoumene helenístico sempre foi fortemente separado por profundas divisões acadêmicas, essa falta de comunicação é prejudicial”, uma vez que perpetua o tratamento antigo, colonialista e helenocêntrico do periodo.

Nesse sentido, o surgimento dos surveys os levantamentos de superficie -, durante a arqueologia processual, trouxe novas possibilidades de abordagem e interpretação arqueológicas (ver Snodgrass 1987; 15; Alcock et al. 1994). O ponto mais importante dessa abordagem diacrônica, é que essa metodologia permite a avaliação direta dos temas relacionados às continuidades ou às rupturas nos diferentes âmbitos de uma sociedade. A comparação de dados de longos periodos de tempo permite que cada uma desses periodos seja revisto como parte de uma longa trajetória, ao longo da qual as ocupações gregas são apenas uma das diferentes sociedades que ali se estabeleceram (ver Rapin 2007: 29).

Briant (1982: 314-17) foi o primeiro a chamar a atenção para os resultados do levantamento realizado por Gardin e Lyonnet (1978/ 79), assim como para o reconhecimento tardio de traços claramente não-helenísticos na cultura material de Ai-Khanum e, portanto, para a demonstração de uma continuidade em periodo greco-bactriano, que perpetuava a estrutura aquemênida preexistente. Isso remete exatamente à questão abordada anteriormente sobre a metodologia utilizada para estabelecer a cronologia de ocupação dos sitios pois, como vimos, o DAFA e o próprio Gardin (1998) atribuiram o início e o final da ocupação de Ai-
Khanum apenas ao periodo greco-bactriano, o que pode ser considerado um problema metodológico grave. Embora a pesquisa do material cerâmico, fornecida por Lyonnet (1997), não tenha apresentado uma cronologia para o sitio superior a 145 a.C., como também vimos, a observação de Fussman (1996: 246) sobre a existência de uma "cidade circular" aquemênida, Kohna Qala, a menos de $2 \mathrm{~km}$ do sítio de Ai-Khanum, já é, em si, uma questão que mereceria extrema atenção. Assim como o é, também, a discussão sobre o suposto abandono da cidade após a chegada dos kushan, como vimos anteriormente.

Nesse sentido, a existência de edifícios de estilo persa na própria cidade de Ai-Khanum descritos mais tarde por Bernard (1994: 110-11) como "inspirados pela arquitetura iraniana e centro-asiática", mas cuja decoração "permaneceu fiel ao gosto grego", também requer cuidado. Embora isso se aplique, por exemplo, ao palácio, o mesmo não pode ser dito dos santuários e templos que aparecem claramente descritos como uma "grande surpresa" pois que sua arquitetura não apresenta "nada em comum com a tradição grega" (Bernard 1994: 115). Apesar de que, de acordo com o próprio Bernard, os templos tivessem abrigado cultos a divindades gregas embora, pelo menos um deles, estivesse diretamente associado a "cultos iranianos" (sic) - i.e., persas. Evidências, em outros sítios da região bactriana, cujos templos apresentam arquitetura oriental, embora escassas, foram encontradas por exemplo em Takht-i Sangin (Litvinsky e Pichikyan 1981: 197 200). Apesar das evidências, Bernard (1994: 116) não forneceu uma cronologia precisa dos edifícios de culto e não formulou qualquer hipótese acerca dessa importante questão ou sobre suas possiveis implicações e usos politicoideológicos, restringindo-se a discorrer sobre um possivel sincretismo entre deuses gregos e regionais. Portanto, não sabemos nem ao menos se os templos são anteriores (associados a Kohna Qala?) ou contemporâneos dos edificios propriamente gregos, como o teatro, entre outros. A respeito da arquitetura dos três templos, algo semelhante foi afirmado por Leriche (2007: 141) e Lecuyot (2007: 158). 
Sendo que esse último pesquisador acrescentou que as plantas das habitações não eram gregas, apenas a decoração dos pórticos nos seus pátios (Lecuyot 2007: 158-59). Leriche (2007: 141, 143), além de observar que a cidade baixa de Ai-Khanum não possuiu uma grade ortogonal, como a maioria das cidades helenísticas do Oriente Próximo, acrescentou que, somente os quarteirões da área sul, ocupados pelas casas da aristocracia, foram organizados em ruas ortogonais. Além disso, esse pesquisador menciona vestigios de fortificações na cidadela de Ai-Khanum de periodo kushan, algo igualmente intrigante, se considerarmos que muralhas não costumam ser construções de caráter temporário ou realizadas para ser rapidamente abandonadas. A visão moderada de Leriche (2007: 142) procura atualmente explicar a ocupação de Ai-Khanum, embora "inquestionavelmente grega", como possuidora de um grau de originalidade maior do que outras fundações helênicas orientais urbanas, obtido graças ao equilibrio entre a estrutura de poder grega, as crenças e o modo de vida da população de caráter misto que a habitou. Por estar distante das rotas comerciais, Ai-Khanum não teria possuido um papel econômico significativo e, por isso, depois dos gregos a sua existência teria se tornado supérflua (Leriche 2007:144), o que explicaria seu abandono posterior.

Estas informações e a ausência de uma cronologia precisa tornam realmente questionável a afirmação de que a cidade de Ai-Khanum tenha sido fundada em "solo virgem" e/ou mesmo abandonada definitivamente após a época greco-bactriana. Nesse sentido, o surgimento e a ruptura brusca e monolitica do periodo grecobactriano nos remete ao tipo semelhante de formulação teórica que buscou explicar o suposto abandono das cidades da civilização do Vale do Indo como devido à invasão de uma civilização supostamente superior - os falantes de indo-ariano, sub-grupo do indo-europeu -, mas cuja teorização, embora reiterada durante décadas a fio, atualmente não mais se confirma (ver Aldrovandi 2006: 206-30). O que não se observa, certamente, no discurso sobre AiKhanum é uma teoria semelhante a respeito da chegada dos kushan pois, nesse caso, as invasões nômades são o sinônimo claro de uma suposta "barbárie". Assim, no discurso acadêmico etnocêntrico reificado, os resultados da invasão ou da chegada de populações em uma determinada região, no caso da Ásia, dependem ironicamente - de seu sentido: se vindos do ocidente são considerados positivos mas, se provenientes de territórios orientais, negativos.

Por isso, em relação à dinâmica regional que precedeu a época greco-bactriana também é necessária uma abordagem mais equilibrada. Esse quadro de uma aceleração geral em época greco-bactriana, como vimos, foi uma generalização baseada em evidências arqueológicas limitadas, fundamentadas em comparações com outras áreas da Báctria e de outras porções orientais do mundo Helenístico (ver Gardin e Gentelle 1979: 23; Holt 1984a, 1984b). Uma vez verificada, a herança dos regimes anteriores nessa região surgiu clara e amplamente refletida, pois o aumento da complexidade social, da urbanização, do crescimento populacional e a implementação da tecnologia agricola remontam aos periodos precedentes. Como vimos, na Báctria, o crescimento demográfico e econômico em época greco-bactriana aparece como parte de um processo de desenvolvimento regional de longa duração (Briant 1982: 95 135; Gardin 1998). O grande desenvolvimento observado nunca será explicado satisfatoriamente pelo fato de os gregos terem conquistado e controlado esse território, mas, mais provavelmente, pelo fato de que ele foi incorporado, reincorporado e influenciado por entidades politicas poderosas. Como bem observou Alcock (1994: 189), nesse caso, o imperialismo foi mais significativo e, mesmo, anterior à própria helenização.

A partir da análise quantitativa sistemática das sub-regiões da Báctria oriental, ora apresentada, foi possivel verificar a dinâmica espacial dos assentamentos tanto de modo sincrônico, em cada um dos periodos, quanto diacrônico, ao longo dos periodos sucessivos. Embora, como vimos, algumas sub-regiões tenham apresentado um crescimento constante até o periodo greco-bactriano e um certo declínio em época kushan, outras sub-regiões revelaram um 
processo inverso, em que a ocupação decresceu após o periodo aquemênida mas, em alguns casos, foi retomada em época kushan. Outras, ainda, apresentaram um grande crescimento em época aquemênida, mas foram praticamente abandonadas nos períodos seguintes. Algumas delas permaneceram estáveis em periodos sucessivos e somente em época kushan se comportaram de maneira distinta. As subregiões com ocupações extremamente baixas dificilmente fornecem um quadro passivel de interpretação, a não ser pelo fato de possuírem um indice maior de ocupação em época kushan. São essas interações regionais, aqui analisadas quantitativamente, que permitem observar a dinâmica e a fluidez da ocupação espacial bactro-oriental.

Existem, no entanto, uma série de lacunas, muitas delas mencionadas ou reiteradas de modo veemente por Gardin (1998) ao longo de seu trabalho, que dificultam a análise mas que, como observamos anteriormente, não a impedem, como por vezes esse arqueólogo afirmou, acreditando que os dados são insuficientes para quase todo tipo de análise e interpretação. O que queremos aqui, certamente não é criticar o trabalho árduo e meritório empreendido por Gardin e sua equipe, não somente em campo, mas também ao longo das duas décadas que se seguiram após as prospecções, trabalho esse que, assim como aquele desenvolvido por Bernard, hoje não poderia mais ter sido realizado, se considerarmos as guerras recorrentes que ainda assolam a região e destruíram grande parte do registro arqueológico in situ. Como havia observado o próprio Gardin (1998: 110), a análise espacial dos sítios seria o passo seguinte e natural a ser desenvolvido. $\mathrm{O}$ pesquisador sugeriu conjugar, por exemplo, os "lugares fortificados" a outros "lugares centrais", dotados de funções mais variadas, mas, apesar disso, permaneceu convencido de que esse exercício formal seria demasiado frágil, pois não poderia levar em conta as circunstâncias particulares que comandaram a constituição dos dados no espaço e no tempo. Isto, embora em parte verdade, não nos parece uma justificativa suficiente, pois a Arqueologia é uma ciência certamente não afeita, mas, já acostuma- da - por sua própria natureza e tipo de registro restrito - a trabalhar dentro dos limites impostos pelos vestígios recuperados.

O desenvolvimento de novas técnicas de análise espacial, mencionadas anteriormente, tem contribuido sobremaneira para embasar as interpretações sobre o registro arqueológico de sociedades passadas. É necessário inovar e não se conformar em repetir, de forma quase mântrica, a mesma razão pela qual algo não foi feito ou não parece nem poder ser realizado. Como bem observou Bradley (1993: 133), os arqueólogos e outros profissionais envolvidos em processos criativos possuem muitas afinidades - como, por exemplo, os atos intuitivos, o reconhecimento de padrões e a associação entre observações e idéias antes sem relação -, ignorar outras possibilidades significa permanecer preso ao que esse pesquisador denominou um solipsismo debilitante. Sob esse ponto de vista, talvez a ausência de uma sistematização diacrônica da distribuição espacial dos assentamentos nos mapas de Gardin (1998) tenha contribuido para sua argumentação e reforçado sua idéia de que não era possivel desenvolver uma análise espacial quantitativa da região bactro-oriental que escapasse do mero formalismo. Já existem, entretanto, estudos recentes que vêm utilizando alguns desses métodos (ver Petrie 2007; Stride 2007). O próprio Stride (2007: 108) considera os territórios da Báctria como instrumentos poderosos para interpretar o desenvolvimento dos assentamentos, pois eles podem ser analisados, descritos e classificados de acordo com suas principais caracteristicas e, principalmente, de modo independente das evidências histórica e arqueológica. Esse pesquisador propõe desenvolver uma tipologia de territórios e regiões, que possibilite propor um quadro interpretativo geral para a Báctria. Sua análise é interessante porque, em certos casos, ocupações antes consideradas como prováveis centros urbanos regionais, quando analisadas diante do ambiente e da ecologia humana disponiveis no passado, foram redimensionadas e esses padrões de assentamento acabaram por apresentar proporções diferentes daquelas anteriormente atribuidas aos mesmos (Stride 2007: 108-114). 
Outro tipo de análise, voltada ao reconhecimento de padrões de ocupação espacial, que chamou nossa atenção durante a pesquisa e sobre a qual pretendemos nos debruçar em um momento futuro, diz respeito à Arqueologia Fractal (ver Brown et al. 2005; Zubrow 2007; Aldrovandi et al. 2010). Como vimos, as interações regionais na bactria-oriental se refletem, por exemplo, na interessante concepção de paisagens como palimpesestos de Thomas (2001: 165-66), na qual o ambiente construido é reapropriado reescrito - de modo recorrente em um dado território. A morfogênese espacial bactrooriental, se concebida em forma de construto imagético, revela um tipo de dinâmica passível de ser analisada a partir da geometria fractal, capaz de revelar e refinar a compreensão acerca das forças de expansão e retração, aparentemente aleatórias, a operar nessa região. Nesse sentido, as formações fractais referem-se às diferentes interações e mutações espaciais apresentadas por uma determinada área geográfica, às relações espaciais intrasitio ou à estrutura regional dos padrões de assentamento ali existentes sincrônica e diacronicamente, algo que a Geografia Urbana vem estudando desde a década de 1990 (ver Lam e De Cola 1993; Tannier e Pumain 2005).
As pesquisas realizadas na Báctria, como vimos, reforçam a necessidade de se evitar quaisquer divisões arbitrárias e posturas etnocêntricas em relação ao passado. Não parece ser uma mera coincidência que os iranianos atuais e seu temido programa nuclear, seguindo a trilha paradigmática dos antigos aquemênidas, continuem a figurar no discurso ocidental como os grandes inimigos. Uma vez desfeitos os limites cronológicos predeterminados e à medida que mais projetos interdisciplinares forem desenvolvidos com as novas tecnologias disponiveis, muitas das dificuldades encontradas atualmente poderão ser transpostas. Ao mesmo tempo, os resultados alcançados pelas pesquisas mais recentes têm viabilizado interpretações mais precisas sobre as sociedades antigas e sobre o caráter das interações entre o Ocidente e o Oriente. Nesse sentido, entretanto, muitas muralhas ainda precisam ruir.

\section{Agradecimentos}

Ao Labeca e às profas. E. Hirata e M. B. Florenzano pelo apoio constante ao longo desta pesquisa. Aos funcionários do ASI pela ajuda durante a escavação bibliográfica. À Fapesp, pelo financiamento da pesquisa.

ALDROVANDI, C.E.V. Spatial morphogenesis in ancient Bactria: interactions and paradigms in a fractal landscape. Revista do Museu de Arqueologia e Etnologia, São Paulo, 20: 163-196, 2010.

Abstract: A quantitative analyses of the spatial morphogenesis of ancient Bactria is presented based on the results provided by the excavations and surveys undertaken during de 1970's in the eastern part of this region, through synchronic and diachronic scales, which comprise almost III milenia of Central Asia's history, ranging from the Bronze Age to the Kushan Period. Based in a perspective from Spatial Archaeology, this analytical framework allows examining the impact of the Greco-Bactrian development in this landscape, as well as evaluating some issues concerning the paradigmatic discourse which pervades the interaction between Greek and other populations settled in Bactria during antiquity.

Keywords: Bactria - Ai-Khanum - Spatial morphogenesis - Built environment - Fractal landscape. 


\section{Referências bibliográficas}

ABETEKOV, A.; YUSUPOV, H.

1994 Ancient Iranian Nomads in Western Central Ásia. In Harmatta, J. (Ed.) History of Civilizations of Central Asia, Volume II. The Development of sedentary and nomadic civilizations: 700 B.C. to A.D. 250. Paris, Unesco Publishing: 23-33.

ALCOCK, S.E.

1994 Breaking up the Hellenistic world: survey and society. In: Morris, I. (Ed.). Classical Greece: Ancient Histories and Modern Archaeologies. Cambridge, Cambridge University Press: 171-190.

ALCOCK, S.E.; CHERRY, J.F.; DAVIS, J.C.

1994 Intensive survey, agricultural practice and the Classical Landscape of Greece. In: Morris, I. (Ed.) Classical Greece: Ancient Histories and Modern Archaeologies. Cambridge: University Press: 137-170.

ALDROVANDI, C.E.V.

2006 As Exéquias do Buda Sakyamuni: morte, lamento e transcendência na iconografia indiano-budista de Gandhara. Tese de Doutorado, Universidade de São Paulo, São Paulo.

2009a A Fronteira Oriental do Mundo Helenístico: as Fontes Escritas sobre o Ambiente Construido e a Sociedade nas Cidades Gregas da Região BactroGandhariana. Revista Archai, Brasilia, n. 03: 45-58, Jul. Disponivel em <http:// archai.unb.br/revista>.

2009b Arqueologia do ambiente construido: uma incursão pelos fundamentos teórico-metodológicos. In: Florenzano, M.B.B.; Hirata, E.F.V. (Orgs.) Estudos sobre a Cidade Antiga. São Paulo, EDUSP - FAPESP, v. 1: 12-33.

ALDROVANDI, C.E.V.; CUSTODIO, C.T.; SCATENA, R.

2010 Modelos imagéticos urbanos e a compreensão da sócio-morfogênese da cidade antiga. In: Hirata, E.F.V.; Kormikiari, M.C.P; Aldrovandi, C.E.V. Estudos sobre o

ALLCHIN, F.R. espaço na antiguidade (no prelo).

1957 The Culture Sequence of Bactria. Antiquity, 21: 131-41.

ASKAROV, A.

1992 The beginning of the Iron Age in Transoxiana. In: Dani, A.H.; Masson, V.M. (Eds.) History of Civilizations of Central Asia, vol. I, The dawn of civilization: earliest times to 700 B.C. Paris, Unesco Pub.: 451-458.

BERNARD, P.

1967 Ai Khanum on the Oxus: a Hellenistic city in Central Asia. Proccedings of the British Academy, 53: 71-95.

1974 Aux confins de l'orient barbare: Ai Khanoum, ville coloniale grecque. Archaeologia-Dossiers de l'Archeologie, 5: 99-114.

1976 Les traditions orientales dans l'architecture gréco-bactrienne. Journal Asiatique, 264: 245-75.

1981 Problèmes d'histoire coloniale grecque à travers l'urbanisme dúne cité hellénistique d'Asie Centrale. 150 Jarhe. Deutsches Archaologisches Institut 1829-1979. Mainz: 108-20.

1982 An ancient Greek city in Central Asia. Scientific American, 246: 148-59.

1994 The Greek Kingdoms of Central Asia. In: Harmatta, J. (Ed.) History of Civilizations of Central Asia, Volume II. The Development of sedentary and nomadic civilizations: 700 B.C. to A.D. 250. Paris, Unesco Publishing: 99-129.

BHABHA, $\mathrm{H}$.

1994 The Location of Culture. London: Routlegde. BOARDMAN, J.

2007 Central Asia: West and East. In: Cribb, J.; Hermann, G. (Eds.) After Alexander: Central Asia before Islam. Proceedings of the British Academy 133. Oxford, Oxford University Press: 9-25.

BOPEARACHCHI, O.

1990 Graeco-Bactrian issues of the later IndoGreek kings. Numismatic Chronicle, 150: 79-103.

BRADLEY, R.

1993 Archaeology: the loss of nerve. In: Yoffee, N.; Sherratt, A. (Eds.) Archaeologycal theory: who sets the agenda? New Directions in Archaeology. Cambridge, Cambridge University Press: 131-33.

BRIANT, P.

1982 Rois, tributs et paysans. Paris: Les Belles Lettres.

1984 L'Asie Centrale et les royaummes procheorientaux du premier millénaire (c. VIIle et Ier siécles avant notre ères). Paris: Ed. Recherches sur les Civilisations.

1996 Histoire de l'empire perse, de Cyrus à Alexandre. Paris: Fayard. 
BROWN, C.T.; WITSCHEY, W.R.T.; LIEBOVITCH, L.S.

2005 The Broken Past: Fractals in Archaeology. Journal of Archaeological Method and Theory, 12 (1) March: 37-78.

CLARKE, D.

1973 Archaeology: the Loss of Innocence. Antiquity, 47: 6-18.

CUNNINGHAM, A.

1871 The Ancient Geography of India. I. The Buddhist Period, including The campaigns of Alexander, and the Travels of Hwen-Thsang. London: Trubner \& Co. (2005).

DANDAMAYEV, M.A.

1994 Media and Achaemenid Iran. In: Harmatta, J. (Ed.) History of Civilizations of Central Asia, Volume II. The Development of sedentary and nomadic civilizations: 700 B.C. to A.D. 250. Paris, Unesco Publishing: 35-65.

DANI, A.H.; BERNARD, P.

1994 Alexander and his Successors in Central Asia. In: Harmatta, J. (Ed.) History of Civilizations of Central Asia, Volume II. The Development of sedentary and nomadic civilizations: 700 B.C. to A.D. 250. Paris, Unesco Publishing: 67-97.

DRENNAN, R.D.

1996 Statistics for Archaeologists, a commonsense approach. New York: Plenum Press.

ENOKI, K.; KOSHELENKO, G.A.; HAIDARY, Z.

1994 The Yüeh-chih and their Migrations. In: Harmatta, J. (Ed.) History of Civilizations of Central Asia, Volume II. The Development of sedentary and nomadic civilizations: 700 B.C. to A.D. 250. Paris, Unesco Publishing: 171-189.

KENOYER, J.M.

1998 Ancient cities of the Indus Valley Civilization. Oxford: Oxford University Press.

FÉDOROV-DAVYDOV, G.

1985 La grande civilisation de l'Asie centrale. In: Yanine, V.; Fédorov-Davydov, G.; Tchernykh, E.; Chélov, D. (Eds.) Fouilles et Recherches Archéologiques en URSS. Moscou, Ed. du Progrès: 174-211.

FOUCHER, A.

1942-7 La Vieille Route de l'Inde de Bactres à Taxila. Mémoires de la Délégation Archéologique Française en Afghanistan, I, 2 v. Paris: Les Éditions d'Art et d'Histoire.

FRANCFORT, H.P.

1979 Les fortifications en Asie Centrale de l'Age du Bronze à l'époque Kouchane. Centre National de la Recherche Scientifique,
Travaux de l'URA 10, Paris, Unité de Recherches Archéologiques.

1984 Fouilles d'Ai Khanoum, III: Le sanctuaire du temple a redans, 2: Les trouvailles. Mémoires de la Délégation Archéologique Française en Afghanistan, t. XXVII. Paris: De Boccard.

1989 Fouilles de Shortughaï. Recherches sur L'Asie Centrale protohistorique. 2 vols. Paris:

Diffusion De Boccard.

1994 Foundations de Bactriane et de Margiane protohistoriques. In: S. Mazzoni (Ed.)

Nuove Fondazioni nel Vicino Oriente antico: realtà e ideologia. Pisa, Giardine: 269-297.

FUSSMAN, G.

1996 Southern Bactria and Northern India before Islam: A Review of Archaeological Reports. The Journal of the American Oriental Society, 116 (4): 243-60.

GARDIN, J.C.

1998 Prospections Archéologiques em Bactriane Orientale (1974-1978). Descriptions de Sites et Notes de Synthèse. Memoirs de la Mission Archéologique Française en Asie Centrale. Tome IX. Paris: Éditions Recherches sur les Civilisations.

GARDIN, J.C.; GENTELLE, P.

1976 Irrigation et peuplement de la plaine d'Ai Khanoum de l'epoque achemenide à l'epoque musulmane. BEFEO, 63: 59-99.

1979 L'exploration du sol en Bactriane antique. BEFEO, 66: 1-29.

GARDIN, J.C.; LYONET, B.

1978-1979 La Prospection Archéologique de la Bactriane Orientale (1974-1978): premiers résultats. Mesopotamia: Rivista de Archeologia, Epigrafia e Storia Orientale Ântica, XIII-XIV, Istituto di Archeologia dell'Università di Torino. Firenze, Licosa: 99-154.

GENTELLE, P.

1978 Études géographiques de la plaine d'AiKhanoum et de son irrigation depuis les temps antiques. Paris: Éditions du CNRS.

1989 Prospections archéologiques en Bactriane orientale (1974-1978), sous la direction de J.C. Gardin: vol. 1, Données paleogéographiques et fondements de l'irrigation (avec la collaboration de C. Marinucci, F.O. Vallino, J. Trichet). Paris: Diffusion De Boccard.

GUILLAUME, O.

1990 Analysis of Reasoning in Archaeology: a case of Graeco-Bactrian and Indo-Greek Numismatics. New Delhi: Oxford University Press. 
HEIBERT, F.E; CAMBON, P. (EDS.)

2008 Afghanistan: Hidden Treasures from the National Museum, Kabul. Washington D.C.: National Geographic Society.

HOLT, F.

1984a Discovering the lost history of Ancient Afghanistan. The Ancient World, 9: 3-11.

1984b Selected bibliography of recent research and studies on Hellenistic Bactria. The Ancient World, 9: 13-28.

1988 Alexander the Great in Bactria: the formation of a Greek frontier in Central Asia. Mnemosyne, Supplementum 104, Leiden.

KENOYER, J. M.

1998 Ancient Cities of the Indus Valley Civilization. Oxford: Oxford University Press.

LE BERRE, M.; SCHLUMBERGER, D.

1964 Observations sur les remparts de Bactres. Paris, MDAFA 19.

LECUYOT, G.

2007 Ai Khanum Recosntructed. In: Cribb, J.; Hermann, G. (Eds.) After Alexander: Central Asia before Islam. Proceedings of the British Academy 133. Oxford, Oxford University Press: 155-162.

LERICHE, P.

2007 Bactria, Land of a Thousand Cities. In: Cribb, J.; Hermann, G. (Eds.) After Alexander: Central Asia before Islam. Proceedings of the British Academy 133. Oxford, Oxford University Press: 121-153.

LITVINSKY, B.A.

1994 Cities and Urban Life in the Kushan Kingdom. In: Harmatta, J. (Ed.) History of Civilizations of Central Asia, Volume II. The Development of sedentary and nomadic civilizations: 700 B.C. to A.D. 250. Paris, Unesco Publishing: 291-311.

LITVINSKY, B.A.; PICHIKYAN, I.R.

1981 Découvertes dans un sanctuaire du dieu Oxus de la Bactriane septentrionale. RA, fasc. 2: 195-216.

LYONNET, B.

1997 Etude de la ceramique; essai sur l'histoire du peuplement. Memoires de la Mission Archeologique Française en Asie Centrale, vol. V. Prospections archeologiques en Bactriane orientale (1974-1978) sous la direction de J.-Cl. Gardin, vol. II: Paris: Editions Recherche sur les Civilisations.

MUKHAMEDJANOV, A.R.

1994 Economy and Social System in Central Asia in the Kushan Age. In: Harmatta, J.
(Ed.) History of Civilizations of Central Asia, Volume II. The Development of sedentary and nomadic civilizations: 700 B.C. to A.D. 250. Paris, Unesco Publishing: 265-289.

NEGMATOV, N. N.

1994 States in north-western Central Asia. In: Harmatta, J. (Ed.) History of Civilizations of Central Asia, Volume II. The Development of sedentary and nomadic civilizations: 700 B.C. to A.D. 250. Paris, Unesco Publishing: 441-456.

PETRIE, C.

2007 Remote Sensing in Inaccessible Lands: Plains and preservation along old routes between Pakistan and Afghanistan", ArchAtlas, Sept, Edition 4. Disponivel em <http://www.archatlas.org/workshop/ Petrie07.php>. Acesso em janeiro de 2009.

POLLITT, J.J.

1986 Art in the Hellenistic Age. Cambridge: Cambridge University Press.

PUGACHENKOVA, G.A.; DAR, S.R.; SHARMA, R.; JOYENDA, M.A; SIDDIPI, H.

1994 Kushan Art. In: Harmatta, J. (Ed.) History of Civilizations of Central Asia, Volume II. The Development of sedentary and nomadic civilizations: 700 B.C. to A.D. 250. Paris, Unesco Publishing: 331-395.

RAPIN, C.

1992 Fouilles d'Aï Khanoum VIII: La trésorerie du palais hellénistique d'Aï Khanoum. L'apogée et la chute du royaume grec de Bactriane. Mémoires de la Délégation Archéologique Française en Afghanistan, t. XXXIII. Paris: De Boccard.

2007 Nomads and the Shaping of Central Ásia: from the Early Iron Age to the Kushan period. In: Cribb, J.; Hermann, G. (Eds.) After Alexander: Central Asia before Islam. Proceedings of the British Academy 133. Oxford, Oxford University Press: 29-72.

SAID, E.

1978 Orientalism. London: Routledge \& Kegan Paul (Penguin: 2003).

SARIANIDI, V.I.

1992 Food-producing and other Neolithic communities in Khorasan and Transoxiana: Eastern Iran, Soviet Central Asia and Afghanistan. In: Dani, A.H.; Masson, V.M. (Eds.) History of Civilizations of Central Asia, vol. I, The dawn of civilization: earliest times to 700 B.C. Paris, Unesco Pub.: 109-126. 
SCHLUMBERGER, D.

1960 Descendants non-méditerranéens de l'art grec. Syria, XXXVII: 131-66, 253-318.

SHENNAN, S.

1988 Quantifying Archaeology. Edinburgh: Edinburgh University Press.

SNODGRASS, A.

1987 An Archaeology of Greece: the Present State and Future Scope of a Discipline. Berkeley: University of California Press.

STEIN, M. A.

1928 Innermost Asia: Detailed Report of Explorations in Central Asia, Kan-su and Eastern Iran, 5 vols. Oxford: Clarendon Press. Reprint, New Delhi; Cosmo Publications (1981).

1929 On Alexander's Track to the Indus: Personal Narrative of Explorations on the North.West Frontier of India. London: Macmillan \& Co.; New York: Benjamin Blom (1972).

STRIDE, S.

2007 Regions and Territories in Southern Central Asia: what the Surkhan Darya Province tells us about Bactria. In: Cribb, J.; Hermann, G. (Eds.) After Alexander: Central Asia before Islam. Proceedings of the British Academy 133. Oxford, Oxford University Press: 99-117.

TANNIER, C.; PUMAIN, D.

2005 Fractals in urban geography: a theoretical outline and an empirical example.
European Journal of Geography. Cybergeo, Systèmes, Modélisation, Géostatistiques, article 307. Disponivel em <http:// www.cybergeo.eu/index3275.html >. Acesso em julho de 2008.

TARN, W.W.

1951 The Greeks in Bactria \& India. Cambridge: Cambridge University Press.

TARN, W.W.; GRIFFITH, G.T.

1952 Hellenistic Civilization. London: Edward Arnold \& Co.

THOMAS, J.

2001 Archaeology of Place and Landscape. In: Hodder, I. (Ed.) Archaeological Theory Today. Cambridge, Polity Press: 165-186.

TRIGGER, B.

1989 História do Pensamento Arqueológico. São Paulo: Odysseus.

VEUVE, S.

1987 Fouilles d'Ai Khanoum, VI: Le gymnase; architecture, ceramique, sculpture. Mémoires de la Délégation Archéologique Française en Afghanistan, t. XXX. Paris: De Boccard.

ZUBROW, E.B.W.

2007 Remote Sensing, Fractals and Cultural Landscapes: An Ethnographic Prologemma Using U2 Imagery. In: Wiseman, J.R.; Farouk El-Baz (Eds.) Remote Sensing in Archaeology. Nova Yorque, Springer Verlag: 252-80. 